\title{
Altered Metabolism of Phospholipases, Diacylglycerols, Endocannabinoids, and $N$-Acylethanolamines in Patients with Mastocytosis
}

\author{
Anne Lise Ferrara $\left(\mathbb{D},{ }^{1}\right.$ Fabiana Piscitelli $\left(\mathbb{D},{ }^{2}\right.$ Angelica Petraroli $\left(\mathbb{D},{ }^{1}\right.$ Roberta Parente, ${ }^{3}$ \\ Maria Rosaria Galdiero $\left({ }^{1},{ }^{1}\right.$ Gilda Varricchi $\left(\mathbb{0},{ }^{1}\right.$ Giancarlo Marone $\left(\mathbb{0},{ }^{4,5}\right.$ \\ Massimo Triggiani $\left(\mathbb{1},{ }^{3}\right.$ Vincenzo Di Marzo $\mathbb{D}^{2},{ }^{2,6}$ and Stefania Loffredo ${ }^{1}{ }^{1}$ \\ ${ }^{1}$ Department of Translational Medical Sciences and Center for Basic and Clinical Immunology Research (CISI), University of Naples \\ Federico II, WAO Center of Excellence, Naples, Italy \\ ${ }^{2}$ Endocannabinoid Research Group, Istituto di Chimica Biomolecolare-Consiglio Nazionale delle Ricerche (ICB-CNR), Pozzuoli, Italy \\ ${ }^{3}$ Division of Allergy and Clinical Immunology, University of Salerno, Italy \\ ${ }^{4}$ Department of Public Health, University of Naples Federico II, Italy \\ ${ }^{5}$ Monaldi Hospital Pharmacy, Naples, Italy \\ ${ }^{6}$ Canada Excellence Research Chair on the Microbiome-Endocannabinoidome Axis in Metabolic Health, Université Laval, Centre de \\ Recherche de l'Institut Universitaire de Cardiologie et Pneumologie de Quèbec, and Institut sur la Nutrition et les \\ Aliments Fonctionnels, Québec City, Canada
}

Correspondence should be addressed to Maria Rosaria Galdiero; mariarosaria.galdiero@unina.it

Received 30 October 2018; Revised 2 April 2019; Accepted 14 May 2019; Published 1 July 2019

Academic Editor: Enrique Ortega

Copyright (c) 2019 Anne Lise Ferrara et al. This is an open access article distributed under the Creative Commons Attribution License, which permits unrestricted use, distribution, and reproduction in any medium, provided the original work is properly cited.

Background. Mastocytosis is a condition characterized by the expansion and accumulation of mast cells (MCs) in various organs. The symptoms are related to the increased release of MC-derived mediators that exert local and distant effects. MCs are a source and target of phospholipase enzymes (PLs), which catalyze the cleavage of membrane phospholipids releasing lipid mediators (e.g., diacylglycerols (DAGs) and the endocannabinoid (EC) 2-arachidonoylglycerol (2-AG)). To date, there are no data on the role of these lipid mediators in mastocytosis. Here, we analyzed plasma levels of PLA 2 PLC, DAG, ECs, and EC-related $\mathrm{N}$-acylethanolamines in patients with mastocytosis. Methods. In 23 patients with mastocytosis and 23 healthy individuals, we measured plasma $\mathrm{PLA}_{2}$ and PLC activities, DAG, 2-AG, anandamide (AEA), palmitoylethanolamide (PEA), and oleoylethanolamide (OEA). Results. Plasma PLA 2 and PLC activities were increased in mastocytosis patients compared to controls. Concentrations of DAG (18:1 20:4 and 18:0 20:4), two second messengers produced by PLC, were higher in mastocytosis compared to controls, whereas the concentrations of their metabolite, 2-AG, were not altered. AEA was decreased in mastocytosis patients compared to controls; by contrast, AEA congener, PEA, was increased. PLA 2 and PLC activities were increased only in patients with mediator-related symptoms. Moreover, PLC activity was positively correlated with disease severity and tryptase concentrations. By contrast, AEA was negatively correlated with tryptase concentrations. Conclusions. PLs and some lipid mediators are altered in patients with mastocytosis. Our results may pave the way for investigating the functions of these mediators in the pathophysiology of mastocytosis and provide new potential biomarkers and therapeutic targets.

\section{Introduction}

Mastocytosis is a disease characterized by the abnormal proliferation and/or accumulation of clonal mast cells (MCs) in the skin and other organs [1]. The pathogenesis of mastocytosis is related to an activating mutation of the KIT receptor localized on MCs, which leads to uncontrolled MC proliferation [2]. 
Patients with mastocytosis can be classified into two main groups characterized by different clinical courses and prognosis: cutaneous mastocytosis (CM) and systemic mastocytosis (SM) [3]. In CM, MC accumulation is limited to the skin, whereas in SM, at least one extracutaneous tissue is involved. The variants of mastocytosis are shown in Supplementary Table 1 [4]. In the majority of patients with mastocytosis, symptoms are due to the activation and degranulation of MCs and are the consequences of their local or systemic effects [5]. Mediator-related symptoms and clinical signs are found in all variants of mastocytosis and may involve different organ systems [6].

MCs produce a plethora of preformed (histamine, tryptase, etc.) and de novo synthesized (lipids, cytokines, etc.) mediators, which exert different biological effects $[7,8]$. Activated MCs express and release phospholipase enzymes (PLs) which catalyze the cleavage of membrane phospholipids $[9,10]$. There are four classes of phospholipases termed A (PLA), B (PLB), C (PLC), and D (PLD) [11-13], distinguished by substrate specificity, subcellular location, and functional importance of their phospholipid metabolites. Enzymatic processing of phospholipids by PLs converts them into lipid mediators or second messengers (such as diacylglycerols (DAGs), endocannabinoids (ECs), and arachidonic acid (AA)), which activate effector enzymes (such as protein kinase $\mathrm{C}(\mathrm{PKC})$ ) and regulate multiple cellular processes of several cells including MCs [14-16].

Secreted $\mathrm{PLA}_{2}\left(\mathrm{sPLA}_{2} \mathrm{~s}\right)$, expressed by MCs, are released into the extracellular fluid upon cellular activation and modulate cell degranulation [9, 17-19]. This feature of $\mathrm{sPLA}_{2} \mathrm{~s}$ explains their presence in biological fluids of patients with inflammatory diseases including asthma, autoimmune diseases, allergic diseases, and cancer [20-25]. sPLA 2 s can exert their function through cleavage of membrane phospholipids or via receptors [26-29]. Murakami et al. reported that the blocking of the heparin-binding domain of $\mathrm{SLA}_{2}$ suppresses $\mathrm{PLA}_{2}$ group IIA-induced histamine release in murine mast cells [30]. The sPLA 2 s are essential for the release of AA from phospholipids and, thereby, for the production of eicosanoids that are produced in large quantities in patients with mastocytosis [31-34].

PLC together with PLD are essential signals for MC activation and degranulation [10, 35-37]. Hydrolysis of phosphatidylinositol 4,5-bisphospate by PLC, and of phosphatidylcholine by PLD followed by the action of phosphatidic acid hydrolase, is the major source of DAGs in stimulated MCs $[14,38,39]$. DAGs are physiological activators of PKC, and in the case of $s n$-2-arachidonoyl-DAG species, they are also precursors of the endocannabinoid 2-arachidonoylglycerol (2-AG) through the action of DAG lipases (DAGLs). Apart from acting on cannabinoid receptors, 2-AG can also be an alternative precursor of AA and eicosanoids $[14,40]$.

The ECs 2-AG and anandamide (AEA), together with non-EC AEA congeners, i.e., $N$-acylethanolamines like oleoylethanolamide (OEA) and palmitoylethanolamide (PEA), are biosynthesized "on demand" from membrane phospholipids and modulate the functional activities of a variety of cells including MCs [41-43]. However, unlike
2-AG, $N$-acylethanolamines are produced from the action serine hydrolases different from PLs [44]. Yet, PEA possess the ability to reduce both acute and chronic inflammations by downmodulating activated MCs [16, 43, 45-48]. MCs express cannabinoid receptors (CB) [49] that regulate $\mathrm{MC}$ activation [43]. Indeed, CB2 activation by 2-AG and AEA downregulates MC degranulation [50, 51].

Owing to the ability of PLs, DAGs, ECs, and $\mathrm{N}$-acylethanolamines to modulate MC biology (either by directly activating MCs or by catalyzing the production/degradation of other molecules), we have analyzed the plasma concentration or activity of these lipid mediators in patients with mastocytosis.

\section{Methods}

2.1. Study Population. We studied 23 adult patients with mastocytosis (10 males and 13 females; age range: 29-76 years; median age 49 years) followed up at the University of Naples Federico II and at the University of Salerno. Table 1 summarizes the patients' characteristics. None of the patients was on treatment for mastocytosis at the time of blood sampling. Twenty-three healthy individuals (10 males and 13 females; age range: $29-70$ years; median age 43 years) were studied as the control group. Inclusion criteria were the absence of any known chronic or acute pathological condition at the time of enrollment, age $>18$ years, ingestion of any antiinflammatory and immunomodulating drugs at the time of the blood sampling, and expression of written informed consent. Exclusion criteria were the presence of any condition that, in the opinion of the investigator, could interfere with the completion of the study procedures and pregnancy.

Mediator-related symptoms were classified according to severity and frequency as follows: 6 patients had grade 0 (no symptoms), 7 had grade 1 (mild/infrequent: prophylaxis and/or as-needed therapy), 5 had grade 2 (moderate: kept under control with antimediator-type drugs daily), and 5 had grade 3 (severe and frequent: not sufficiently controlled with therapy). None of the patients had grade 4 characterized by a severe adverse event which requires immediate therapy and hospitalization [1].

The diagnosis and classification of mastocytosis were based according to the recommendation of the World Health Organization (WHO) on the histological examination of a skin biopsy for CM and of a bone marrow biopsy for SM [52]. Patients were divided according to cutaneous and/or systemic involvement and assessing the severity and frequency of symptoms. The first group (indolent) included maculopapular cutaneous mastocytosis (MPCM) $(n=2)$, mastocytosis in the skin (MIS) $(n=4)$, bone marrow mastocytosis (BMM) $(n=2)$, and indolent SM (ISM) $(n=7)$. The second group (advanced) included patients with smouldering SM $(\mathrm{SSM})(N=4)$, aggressive SM $(\mathrm{ASM})(N=3)$, and SM associated with hematologic disease (SM-AHD) $(N=1)$. The most common mutation of KIT receptors found in patients with indolent and aggressive SM is KIT D816V [53]. The assessment of KIT D816V mutation was performed in all patients with ASM (3 patients), SSM (5 patients), and SM-AHD (1 patient). Among patients with indolent 
TABLE 1: Characteristics of 23 adult patients with mastocytosis.

\begin{tabular}{|c|c|c|c|c|c|}
\hline Patient no. & Sex & Age & $\begin{array}{l}\text { Disease } \\
\text { category }\end{array}$ & $\begin{array}{c}\text { Tryptase } \\
(\mu \mathrm{g} / \mathrm{L})\end{array}$ & $\begin{array}{l}\text { Symptom } \\
\text { grading }\end{array}$ \\
\hline 1 & $\mathrm{~F}$ & 38 & MIS & 17.2 & 0 \\
\hline 2 & F & 49 & $\mathrm{BMM}$ & 17.8 & 0 \\
\hline 3 & $\mathrm{M}$ & 49 & $\mathrm{BMM}$ & 32.6 & 0 \\
\hline 4 & $\mathrm{M}$ & 62 & ISM & 64.5 & 0 \\
\hline 5 & $\mathrm{M}$ & 66 & SSM & 551 & 0 \\
\hline 6 & $\mathrm{~F}$ & 33 & SM-AHD & 7.9 & 0 \\
\hline 7 & $\mathrm{~F}$ & 29 & MPCM & 11.5 & 1 \\
\hline 8 & $\mathrm{~F}$ & 49 & MPCM & 5 & 1 \\
\hline 9 & $\mathrm{~F}$ & 26 & MIS & 15.8 & 1 \\
\hline 10 & $\mathrm{~F}$ & 45 & MIS & 47.6 & 1 \\
\hline 11 & $\mathrm{M}$ & 50 & MIS & 127 & 1 \\
\hline 12 & $\mathrm{M}$ & 54 & SSM & 216 & 1 \\
\hline 13 & $\mathrm{M}$ & 57 & ISM & 58.4 & 1 \\
\hline 14 & $\mathrm{~F}$ & 42 & ISM & 184 & 2 \\
\hline 15 & $\mathrm{~F}$ & 49 & ISM & 56.5 & 2 \\
\hline 16 & $\mathrm{M}$ & 71 & ISM & 17.6 & 2 \\
\hline 17 & $\mathrm{M}$ & 50 & SSM & 454 & 2 \\
\hline 18 & $\mathrm{~F}$ & 57 & SSM & 112 & 2 \\
\hline 19 & $\mathrm{M}$ & 35 & ASM & 145 & 2 \\
\hline 20 & $\mathrm{~F}$ & 35 & ISM & 32.4 & 3 \\
\hline 21 & $\mathrm{~F}$ & 55 & ISM & 129 & 3 \\
\hline 22 & $\mathrm{~F}$ & 45 & ASM & 36.2 & 3 \\
\hline 23 & M & 76 & ASM & 390 & 3 \\
\hline
\end{tabular}

ASM: aggressive systemic mastocytosis; BMM: bone marrow mastocytosis; ISM: indolent systemic mastocytosis; MIS: mastocytosis in the skin; MPCM: maculopapular cutaneous mastocytosis; SM-AHD: systemic mastocytosis associated with hematologic disease; SSM: smouldering systemic mastocytosis.

mastocytosis, the assessment of KIT mutation was performed in those with high levels of tryptase $(>100 \mathrm{ng} / \mathrm{mL})$. Patient no. 14 and patient no. 21 show the presence of activating KIT mutation. We invited patients with provisional diagnosis of mastocytosis in the skin (4 patients) to undergo a bone marrow biopsy, but they refused. Lipid mediators, such as $\mathrm{PLA}_{2}$, are often lipoprotein-bound or associated with the circulation; therefore, lipid profile (cholesterol, low-density lipoprotein, high-density lipoprotein, and triglycerides) was assessed in all patients and controls. Three patients had a low level of cholesterol (84, 89 , and $73 \mathrm{mg} / \mathrm{dL}$, respectively); the remaining patients and controls had normal lipid profile.

2.2. Plasma Collection. The Ethical Committee Campania ASL Napoli 3 Sud (protocol number 68863) approved that plasma obtained during routine diagnostics could be used for research investigating the physiopathology of mastocytosis, and written informed consent was obtained from patients according to the principles expressed in the Declaration of Helsinki. The controls had been referred for routine medical check-up and volunteered for the study by giving informed consent. The samples were collected by means of a clean venipuncture and minimal stasis using sodium citrate $3.2 \%$. In case of recent anaphylactic reactions, the measurement of all metabolites was performed at least two weeks after the acute event.

2.3. Tryptase. Plasma tryptase concentrations were measured by a fluoroenzyme immune assay (FEIA) using Uni-CAP100 (Phadia Diagnostics AB, Uppsala, Sweden). This technique allowed the measurement of both $\alpha$-tryptase and $\beta$-tryptase. Normal values are $12.5 \mu \mathrm{g} / \mathrm{L}$.

2.4. Phospholipase Activity Assay. A modified liposomalbased fluorescent assay was used to measure PLA 2 activity in plasma (Life Technologies EnzChek ${ }^{\circledR}$ phospholipase $\mathrm{A}_{2}$ assay). Results are expressed as units/L of $\mathrm{PLA}_{2}$ activity.

PLC activity was determined using the EnzChek ${ }^{\circledR}$ Direct Phospholipase C Assay kit (Life Technologies). Results are expressed as units/L of PLC activity.

PLD activity was assessed using a Sigma-Aldrich kit (catalogue number MAK137). This assay evaluates the hydrolysis of phosphatidylcholine to choline by PLD. Results are expressed as units/L of PLD activity.

2.5. Measurement of Endocannabinoids (AEA, 2-AG), $N$-Acylethanolamines (PEA, OEA), and DAGs. Plasma was sonicated and extracted with chloroform/methanol/Tris$\mathrm{HCl} 50 \mathrm{mmol} / \mathrm{L} \mathrm{pH} 7.5$ (2:1:1, vol/vol) containing internal standards $\left(\left[\mathrm{H}_{2}\right] 8\right.$ AEA 5 pmol; $\left[\mathrm{H}_{2}\right] 5$ 2-AG, $\left[\mathrm{H}_{2}\right] 5$ PEA, and $\left[\mathrm{H}_{2}\right] 4 \mathrm{OEA} 50 \mathrm{pmol}$ each) for EC quantification as well as 1,2-heptadecanoin (Larodan AB, Malmo, Sweden) for DAG measurement. The lipid-containing organic phase was dried down, weighed, and prepurified by open-bed chromatography on silica gel with $99: 1,90: 10$, and 50:50 $(v / v)$ chloroform/methanol. The 90:10 fraction was used for EC and $N$-acylethanolamine quantification by LC-APCIMS (LCMS-2020, Shimadzu) as previously reported [54]. DAG levels were measured by LC-MS-MS using an LC20AB coupled to a hybrid detector IT-TOF (Shimadzu Corporation, Kyoto, Japan) equipped with an ESI interface [55].

2.6. Statistical Analysis. Data were analyzed with the GraphPad Prism 5 software package. Data were tested for normality using the D'Agostino-Pearson normality test. If normality was not rejected at the 0.05 significance level, we used parametric tests. Otherwise, for not-normally distributed data, we used nonparametric tests. Statistical analysis was performed by an unpaired two-tailed $t$-test or two-tailed Mann-Whitney test as indicated in figure legends. Correlations between two variables were assessed by Spearman's correlation analysis and reported as coefficient of correlation $(r)$. A $p$ value $\leq 0.05$ was considered statistically significant. Plasma levels of PLA $\mathrm{PL}_{2}$ PLC, DAGs, and ECs are shown as the median (horizontal black line), the $25^{\text {th }}$ and $75^{\text {th }}$ percentiles (boxes), and the $5^{\text {th }}$ and $95^{\text {th }}$ percentiles (whiskers) of 23 controls and 23 patients.

\section{Results}

3.1. PLA $\mathrm{A}_{2}$ and PLC, but Not PLD, Plasma Activities Are Increased in Patients with Mastocytosis. We measured plasma 
$\mathrm{PLA}_{2}$, PLC, and PLD activities in patients with mastocytosis $(N=23)$ and age- and gender-matched healthy controls $(N=23)$ (Figure 1). Both $\mathrm{PLA}_{2}$ (Figure 1(a)) and PLC (Figure 1(b)) activities were increased in patients with mastocytosis compared to controls. There was a positive linear correlation between $\mathrm{PLA}_{2}$ and PLC activities (Figure 1(c)). By contrast, no difference in activity of PLD was found between patients and controls (Figure 1(d)).

There was no correlation between the age and the activity of PLA $\mathrm{P}_{2}$ and PLC in both patients and controls (data not shown). PLA $_{2}$ and PLC activities were higher in male mastocytosis patients (Figures $1(\mathrm{e})$ and $1(\mathrm{f})$ ) whereas there was no gender difference in controls (Figures $1(\mathrm{~g})$ and $1(\mathrm{~h})$ ).

$\mathrm{PLA}_{2}$, in particular group VII, are often lipoproteinassociated [22]. Only three of our patients had altered plasma cholesterol, but no correlation between lipid profile and PLA 2 plasma activity was found in these patients (data not shown).

3.2. Increased DAG Concentrations in Patients with Mastocytosis. To evaluate whether the enhancement of PLC activity was accompanied by an increased production of DAGs, we measured DAG 18:1 20:4 and DAG 18:0 20:4 concentrations in the plasma of mastocytosis patients. Figure 2 shows that both DAG 18:1 20:4 (a) and DAG 18:0 20:4 (b) concentrations in the plasma of mastocytosis patients were higher than in healthy controls. DAG 18:1 20:4 and DAG 18:0 20:4 concentrations were positively correlated with each other (Supplementary Figure 1). Like PLC, DAG concentrations did not correlate with the age of our study populations (data not shown) but were higher in male patients (Figures 2(e) and 2(f)). In mastocytosis patients, the concentrations of DAGs did not correlate with PLC activities (Supplementary Figures 2A-2B), suggesting that alternative sources of DAGs, or reduced DAG catabolism (see below), may occur in these patients or that phospholipid precursor availability, rather than PLC activity, is the limiting step for DAG biosynthesis.

3.3. Endocannabinoids in Patients with Mastocytosis. Unlike the concentrations of its precursors (DAGs) (see above), 2AG concentrations in patients with mastocytosis were similar to controls (Figure 3(a)), although they correlated positively with DAG concentrations (Figures 3(b) and 3(c)). Interestingly, AEA concentrations were lower in patients with mastocytosis compared to controls (Figure 3(d)). By contrast, PEA concentrations were increased in mastocytosis (Figure 3(e)). OEA concentrations did not differ between the two groups (Figure 3(f)).

No correlation was found between age and EC and $\mathrm{N}$-acylethanolamine concentrations in either patients or healthy controls (data not shown). Males exhibited higher levels of 2-AG in both controls and patients compared to females (Figures $3(\mathrm{~g})$ and $3(\mathrm{~h})$ ), whereas no gender differences were found in AEA and PEA concentrations (Supplementary Figures 3A-3F).

3.4. Relationships among PLA $2, P L C, D A G s$, and ECs and Disease Severity. To understand whether altered concentrations of PLs and their metabolites reflected different degrees of disease severity, we used a multiple experimental analysis. First, we analyzed the correlation among lipid metabolites and tryptase because a significant proportion of patients with advanced forms of mastocytosis (ASM and SMAHD) exhibit markedly elevated serum tryptase levels (often $>200 \mathrm{mg} / \mathrm{L}$ ) compared to those with ISM $[44,56]$. PLC (Figure 4(a)), but not PLA 2 (Figure 4(b)) and DAGs (Figures 4(c) and 4(d)), positively correlated with tryptase concentrations in mastocytosis patients. The concentrations of AEA, which are lower in patients (Figure 3(d)), negatively correlated with tryptase concentrations (Figure 4(e)). By contrast, the concentrations of PEA (Figure 4(f)) did not correlate with tryptase.

Next, patients with mastocytosis were grouped according to the severity of mediator-related symptoms, and concentrations of PL, DAGs, AEA, and PEA levels were compared among groups. PLA ${ }_{2}$ and PLC activities were not increased in asymptomatic patients (grading 0 ) as compared to controls (Figures 5(a) and 5(b)). Patients with mediator-related symptoms (grading 1 to 3 ) had elevated PLA 2 and PLC activities compared to both asymptomatic patients and healthy controls (Figures 5(a) and 5(b)). By contrast, DAG concentrations were increased in all groups of mastocytosis patients compared to controls (Figures 5(c) and 5(d)). AEA were generally lower (Figure 5(e)), and PEA were increased in all mastocytosis patients compared to controls, respectively (Figure 5(f)).

Finally, we grouped patients according to their clinical variants in two groups (see Methods): indolent (MPCM/ MIS/ISM/BMM) and advanced (SSM/SM-AHD/ASM) mastocytosis. Figure 6 shows that $\mathrm{PLA}_{2}$ activities (Figure 6(a)), DAGs (Figures 6(b) and 6(c)), AEA (Figure 6(d)), and PEA (Figure 6(e)) concentrations did not differ between patients with indolent and advanced variants but were altered in both indolent and advanced variants when compared to controls. PLC activity, like tryptase, was higher in patients with advanced mastocytosis compared to indolent variants (Figure 6(f)), but unlike tryptase, PLC activities were also increased in indolent mastocytosis compared to controls (Figure 6(g)).

\section{Discussion}

In this study, we describe for the first time that plasma PL activities and concentrations of their metabolites (e.g., DAGs and 2-AG) are significantly altered in patients with mastocytosis. Patients with mastocytosis have (1) increased plasma activities of PLA $\mathrm{P}_{2}$ and PLC, (2) elevated DAGs and PEA concentrations, and (3) decreased levels of AEA. It is well known that PLs control MC degranulation $[9,35]$ and eicosanoid production, two conditions associated with mastocytosis [31-34]. Antagonists and/or inhibitors of synthesis of eicosanoids are currently used to treat mediator-related symptoms in patients with mastocytosis [57, 58]. These observations are in line with the results of our study showing that some of these molecules, in particular PLs, are significantly increased in patients with more severe symptoms and disease phenotype. 


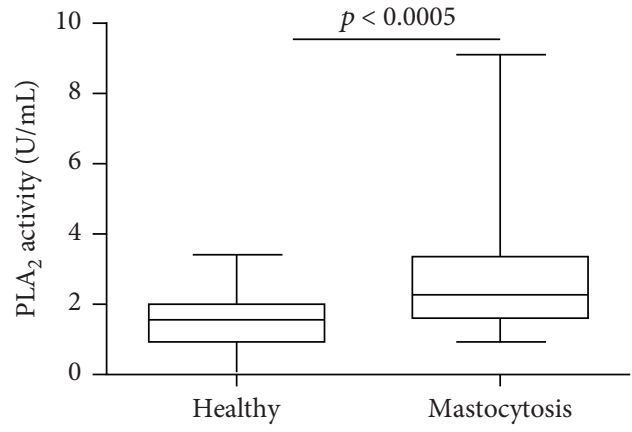

(a)

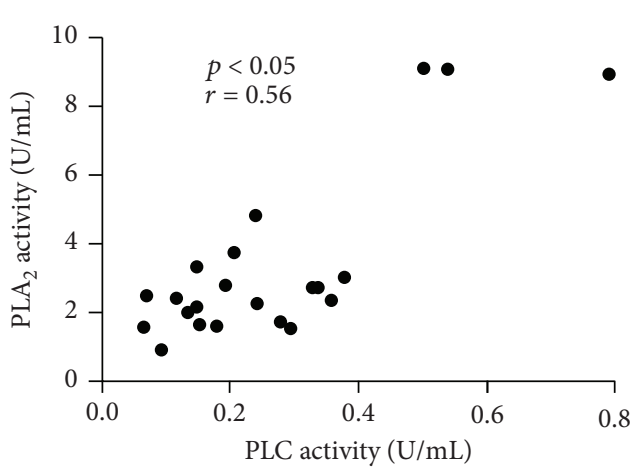

(c)

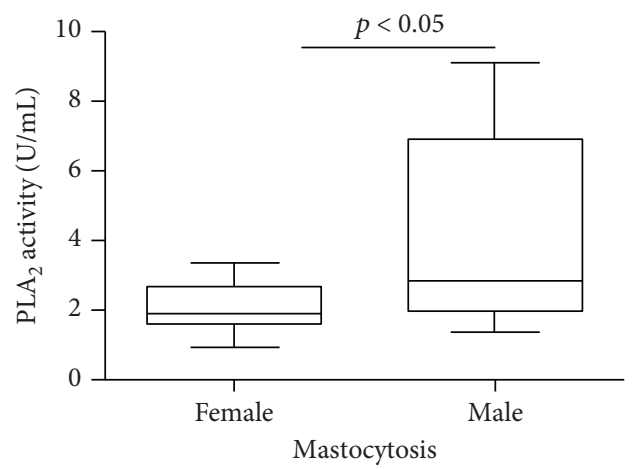

(e)

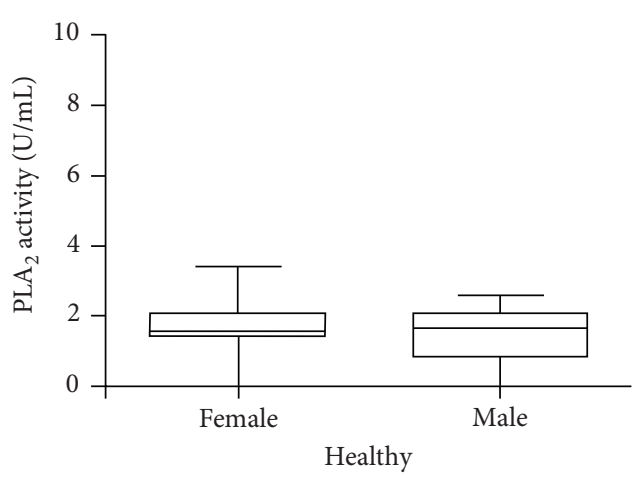

(g)

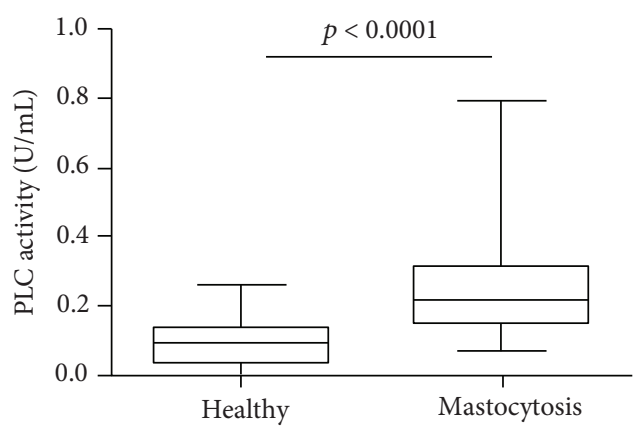

(b)

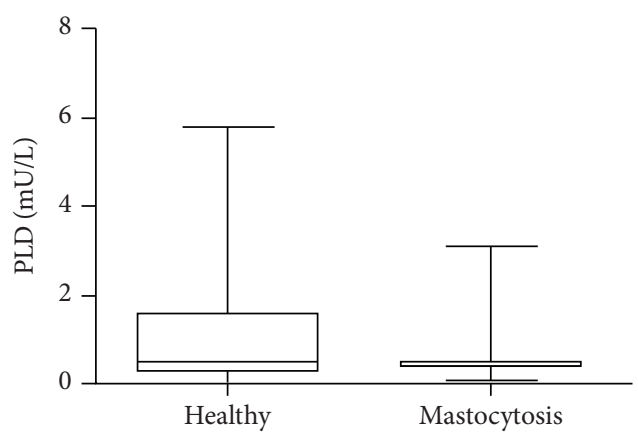

(d)

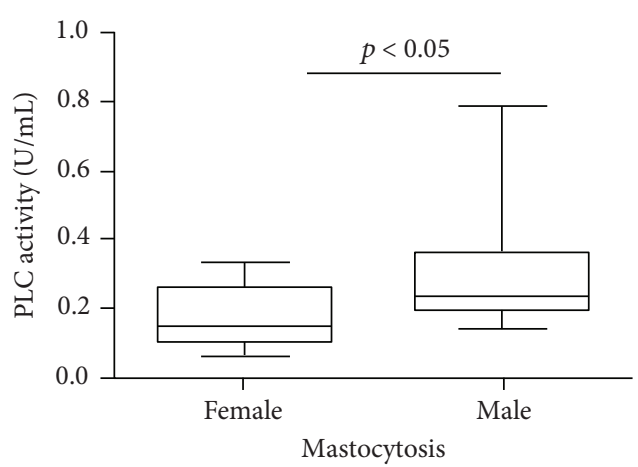

(f)

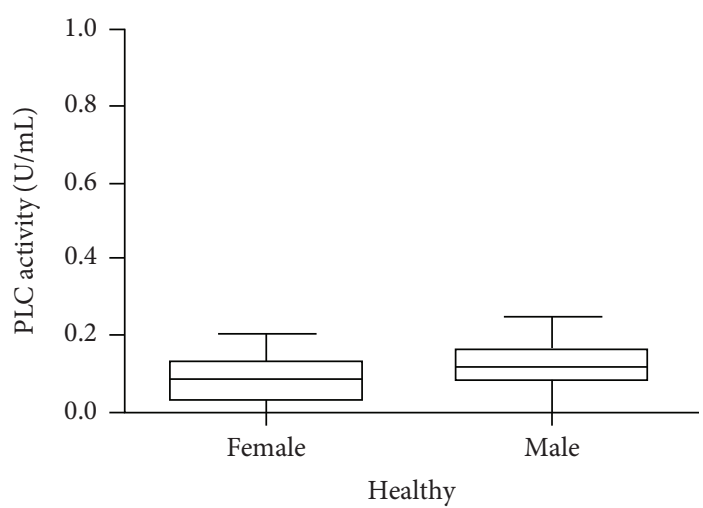

(h)

Figure 1: Activity of PLA 2 , PLC, and PLD in plasma of patients with mastocytosis and healthy controls. Data are shown as the median (horizontal black line), the $25^{\text {th }}$ and $75^{\text {th }}$ percentiles (boxes), and the $5^{\text {th }}$ and $95^{\text {th }}$ percentiles (whiskers) of 23 healthy controls and 23 mastocytosis patients for PLA $_{2}$ (a), PLC (b), and PLD (d) assessment. Correlation between PLA 2 and PLC (c) was assessed by Spearman's correlation analysis and reported as coefficient of correlation $(r)$. PLA 2 and PLC were measured in mastocytosis females and males (e, f) and healthy females and males (g, h). 


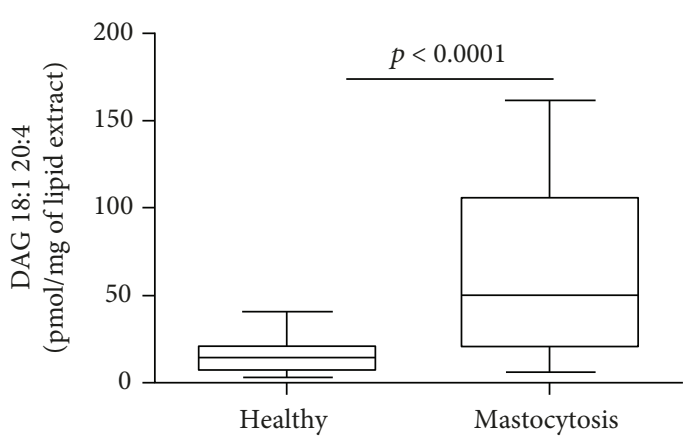

(a)

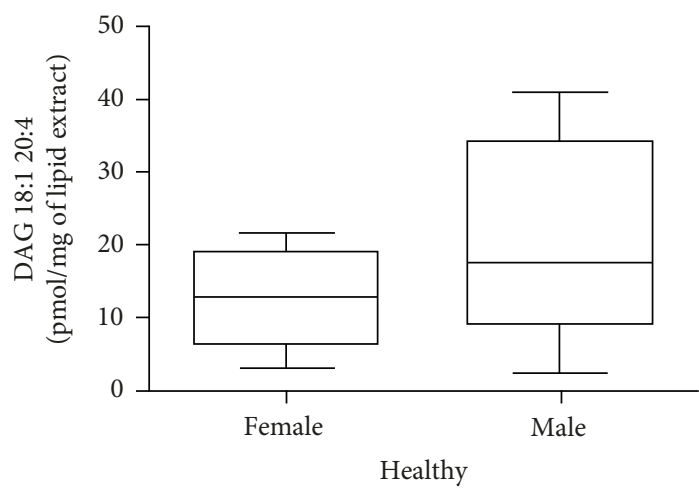

(c)

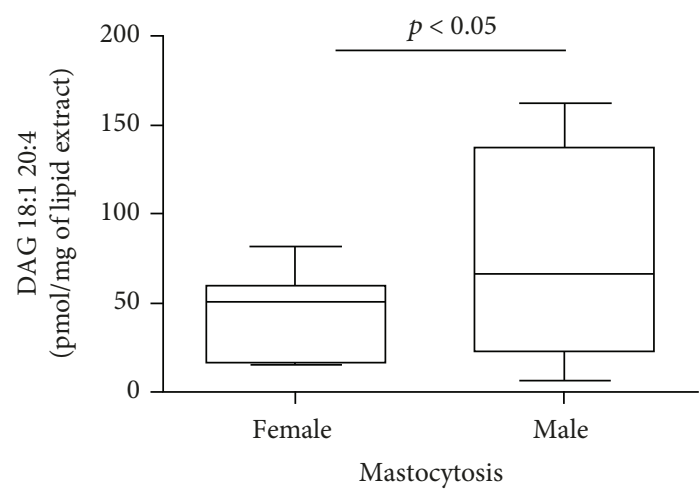

(e)

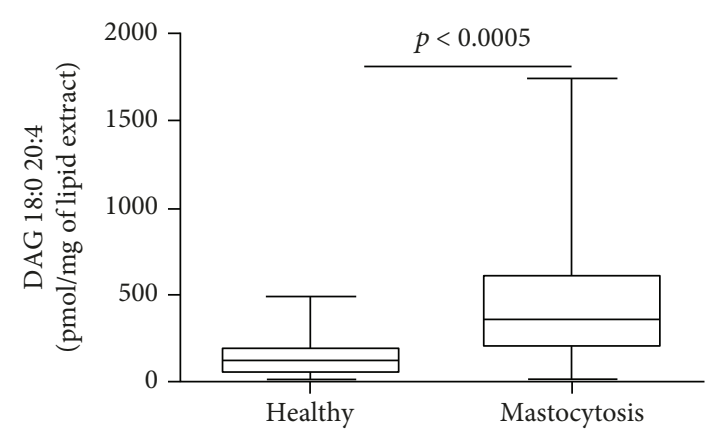

(b)

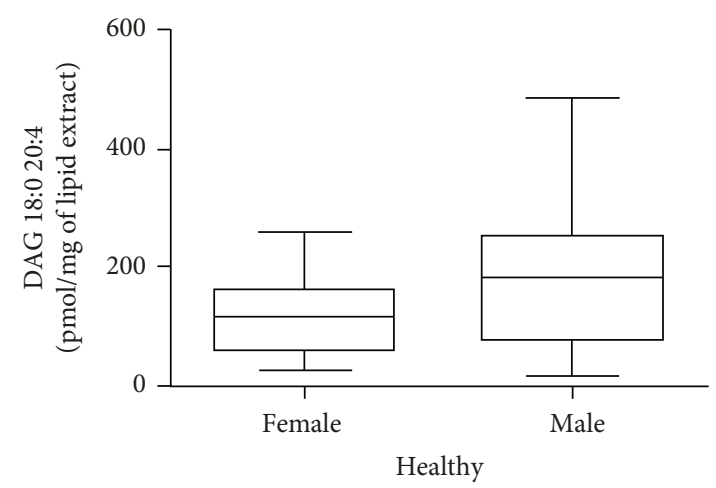

(d)

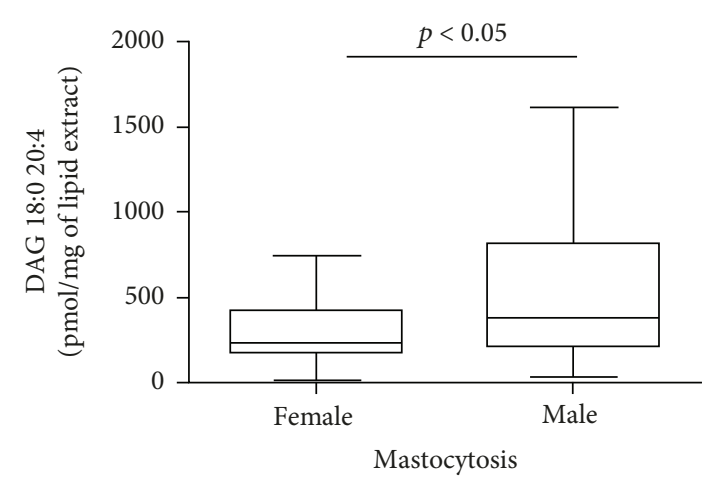

(f)

FIGURE 2: DAG 18:1 20:4 and 18:0 20:4 concentrations in plasma of patients with mastocytosis and healthy controls. DAG 18:1 20:4 (a) and DAG 18:0 20:4 (b) concentrations in healthy controls and mastocytosis patients. DAG 18:1 20:4 and DAG 18:0 20:4 concentrations in healthy females and males (c, d) and in mastocytosis females and males (e, f).

Mastocytosis is caused by an activating mutation of KIT that leads to uncontrolled proliferation and accumulation of MCs with heterogeneous clinical manifestations ranging from cutaneous and advanced forms with poor prognosis $[3,4]$. Our results suggest that PLA 2 and PLC could be involved in the development of mediator-related symptoms in patients with mastocytosis. In fact, $\mathrm{PLA}_{2}$ and PLC activities are increased in symptomatic but not in asymptomatic patients when compared to healthy controls. These data are consistent with the known effects of PLA $\mathrm{P}_{2}$ and PLC on MCs. Indeed, some evidence demonstrates the role of $\mathrm{PLA}_{2}$ in $\mathrm{MC}$ activation through $\mathrm{CPLA}_{2}$ involvement. Kikawada and coworkers reported that in MCs lacking $\mathrm{PLA}_{2}$ group V, the time course of phosphorylation of ERK $1 / 2$ and CPLA $_{2}$ was markedly decreased, leading to attenuation of eicosanoid formation in response to stimulation through TLR2 but not through c-kit or FceRI [59]. Phospholipase C- (PLC-) $\beta 3$ is crucial for FceRI-mediated MC activation [35]. MCs are a source and target of $\mathrm{sPLA}_{2}$, in particular, of group IIA (PLA2G2A) and groups V (PLA2G5) and III (PLA2G3) $[9,18]$. Overexpression of PLA2G2A in rat MCs augments degranulation $[9,17]$ and triggers histamine [30] and $\mathrm{PGD}_{2}$ release [60], whereas overexpression of PLA2G3 leads to spontaneous skin inflammation [9, 61, 62].

Secretory phospholipases are increased in biological fluids of patients with several disease such as inflammatory, cardiovascular, and autoimmune diseases and cancer [23, 63-67]. In this study, we have not assessed the specific 


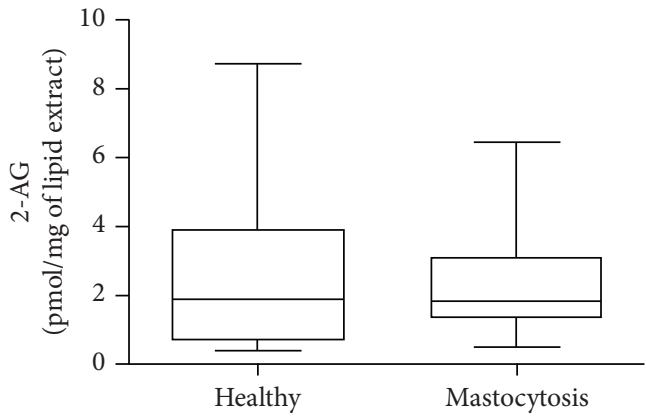

(a)

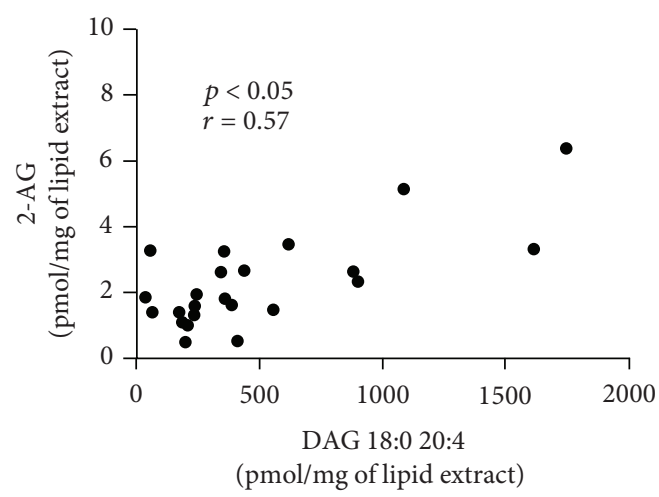

(c)

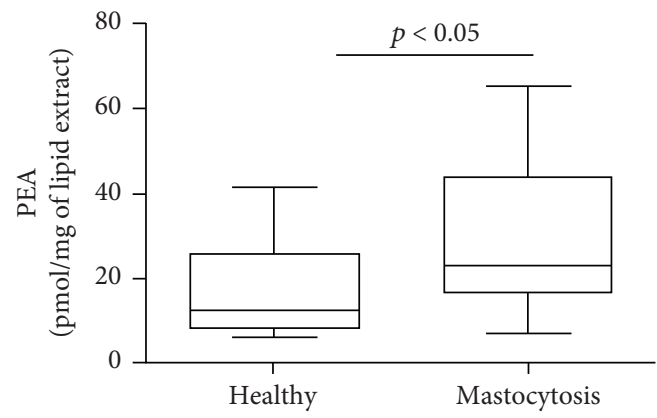

(e)

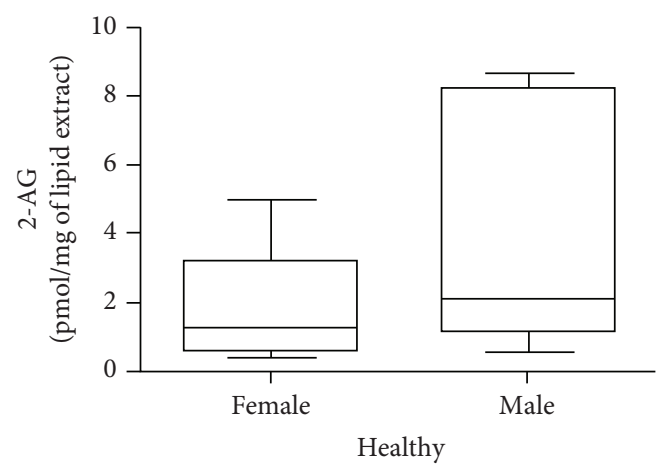

(g)

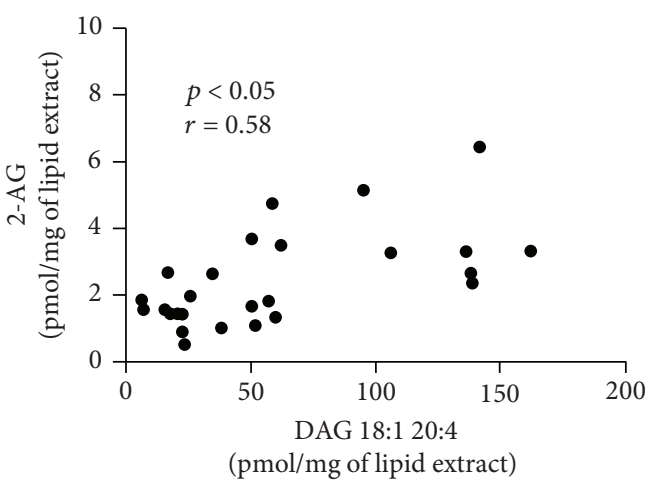

(b)

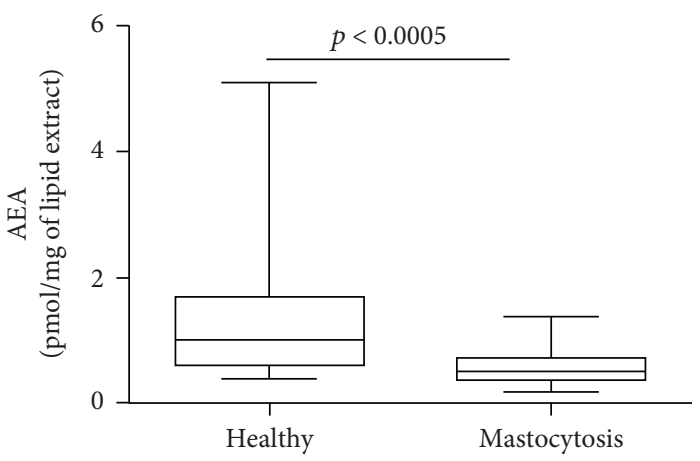

(d)

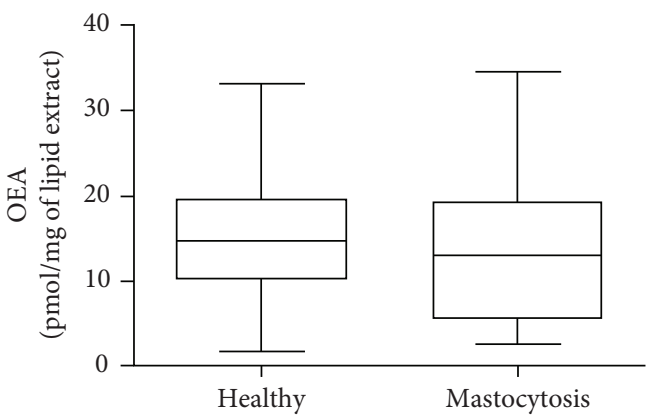

(f)

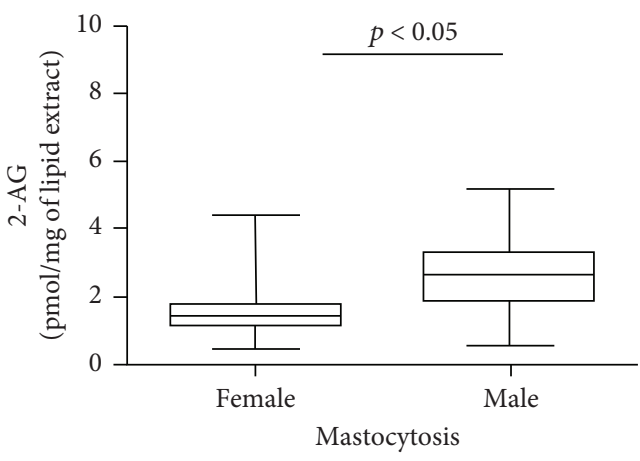

(h)

FIgUre 3: 2-AG, AEA, PEA, and OEA concentrations in plasma of patients with mastocytosis and healthy controls. (a) 2-AG concentrations in healthy controls and mastocytosis patients. Correlation between 2-AG and DAG 18:1 20:4 (b) and DAG 18:0 20:4 (c) was assessed by Spearman's correlation analysis and reported as coefficient of correlation $(r)$. AEA (d), PEA (e), and OEA (f) concentrations in healthy controls and mastocytosis patients. 2-AG concentration in healthy females and males (g) and in mastocytosis females and males (h). 


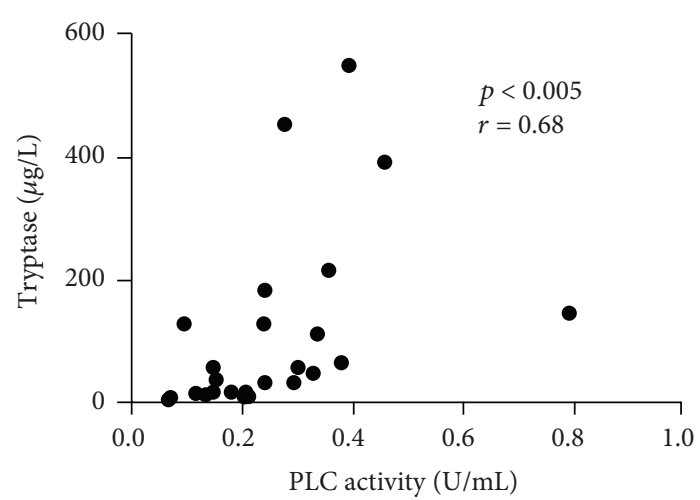

(a)

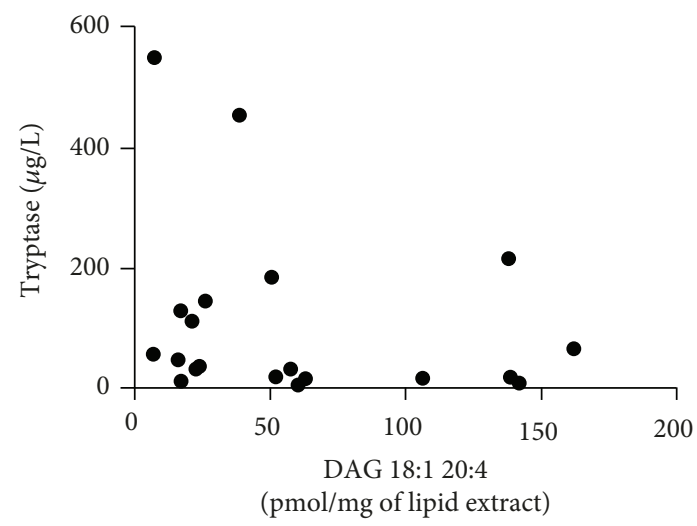

(c)

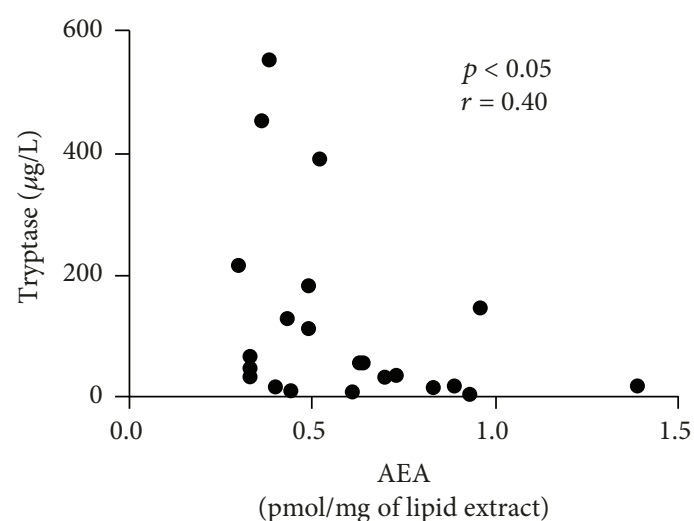

(e)

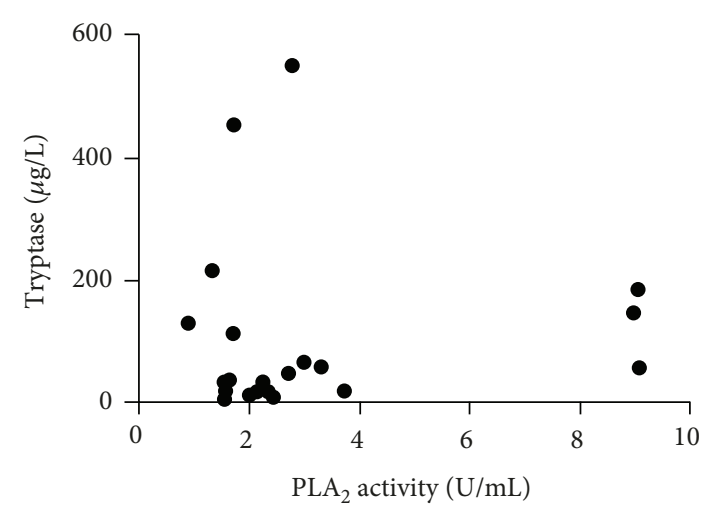

(b)

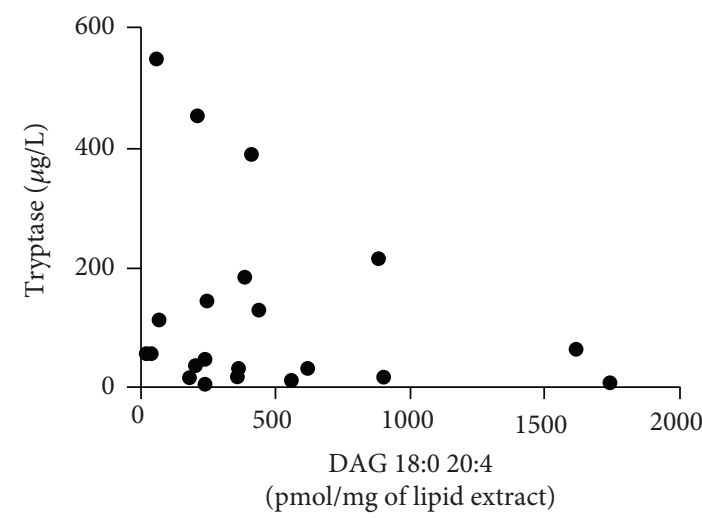

(d)

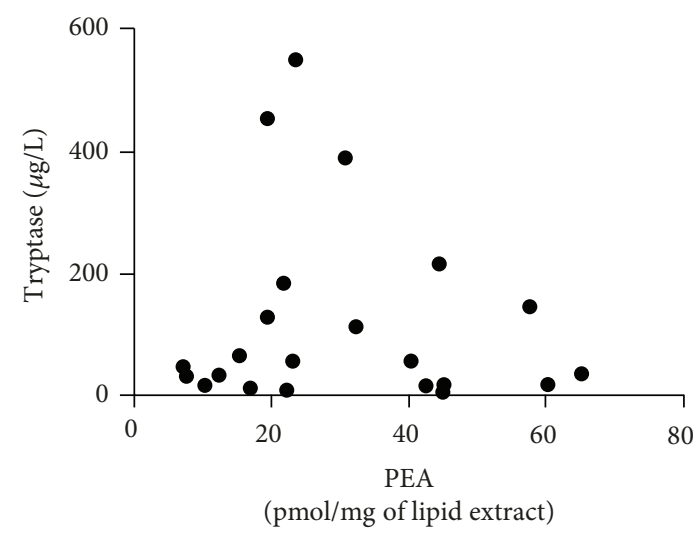

(f)

FIgURE 4: Relationships among PLC, PLA 2 , DAG, ECs, and tryptase concentrations. Correlations between two variables (PLC and tryptase (a), PLA 2 and tryptase (b), DAG 18:1 20:4 and tryptase (c), DAG 18:0 20:4 and tryptase (d), AEA and tryptase (e), and PEA and tryptase (f)) were assessed by Spearman's correlation analysis and reported as coefficient of correlation $(r) . p$ value $<0.05$ was considered statistically significant.

$\mathrm{PLA}_{2}$ group(s) secreted in mastocytosis; however, it is reasonable to hypothesize that PLA2G2A, which is the major secreted form of $\mathrm{PLA}_{2}$ in human serum and plasma $[23,63-67]$, is responsible for most of the detected PLA activity in mastocytosis. A time-resolved fluoroimmunoassay (TR-FIA) on plasma and confocal microscopy analysis of tissue biopsies could identify the existence of types of PLA involved in mastocytosis.

Tryptase is the most widely used circulating marker of mastocytosis $[68,69]$ and is also an easy accessible predictor for disease progression in patients with indolent mastocytosis $[56,68]$. Our results show that most patients with advanced forms of mastocytosis have markedly increased plasma PLC activities compared to those with indolent forms. In addition, PLC activities were positively correlated with tryptase concentrations. It will be interesting to evaluate whether the plasma levels of this enzyme at time of diagnosis could predict the clinical severity of mastocytosis.

Several PLC products such as DAG 18:1 20:4 and DAG 18:0 20:4 are increased in patients with mastocytosis, but 


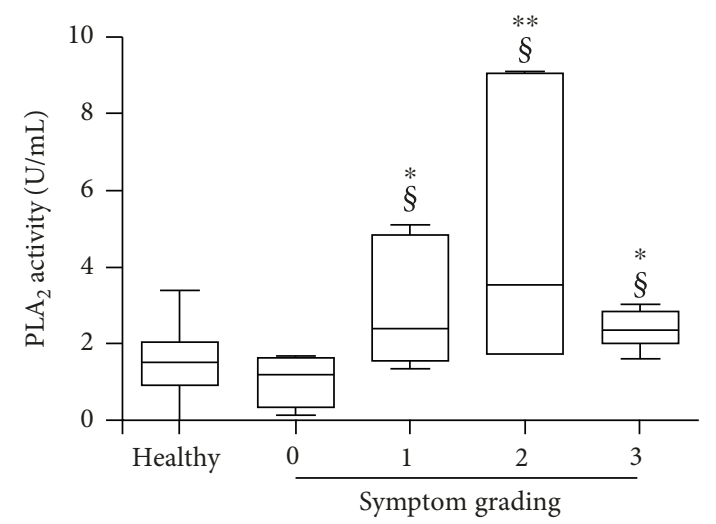

(a)

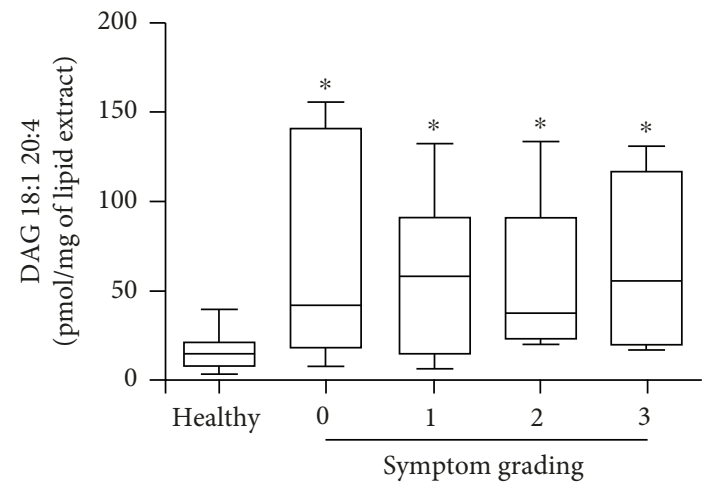

(c)

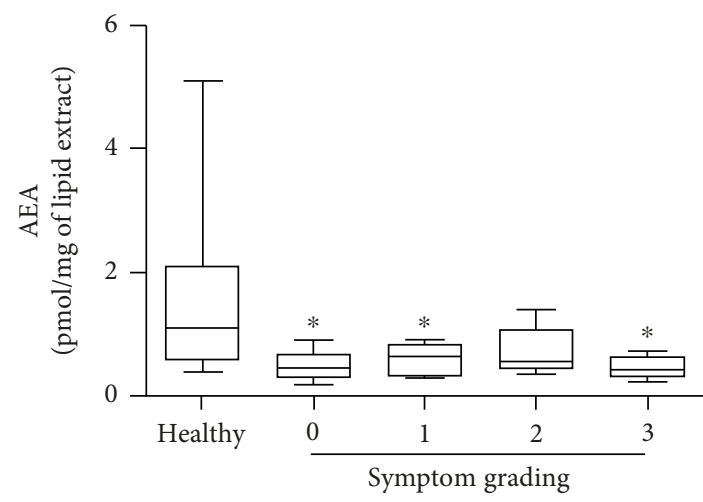

(e)

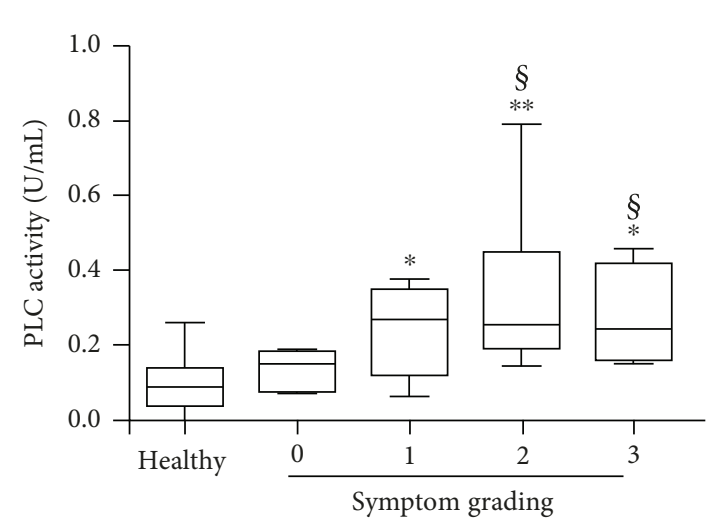

(b)

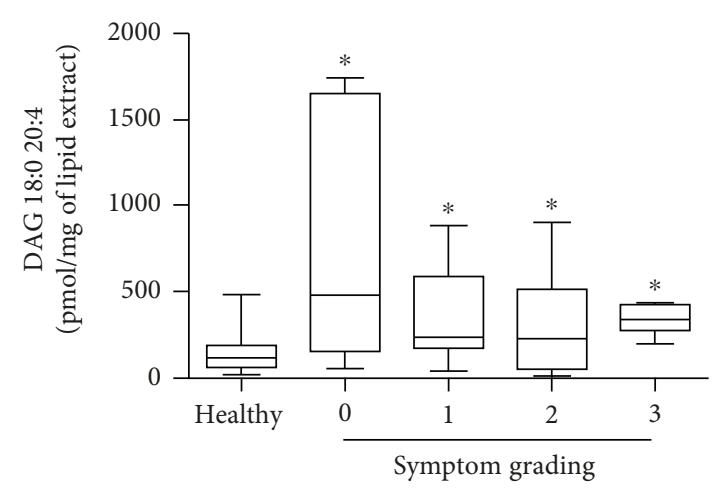

(d)

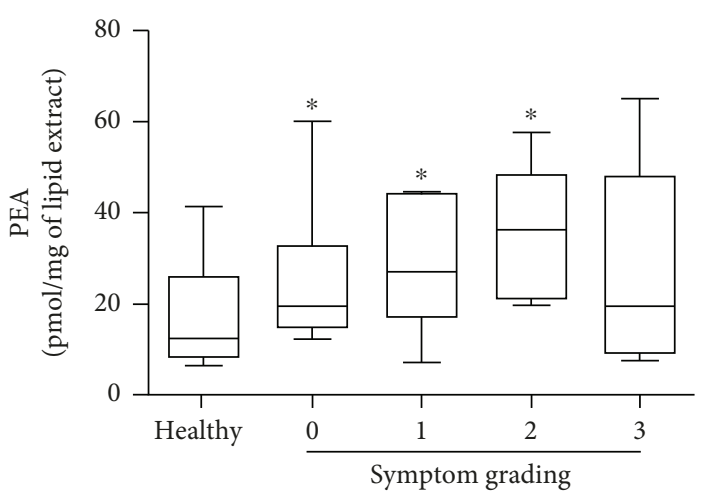

(f)

Figure 5: Relationships among PLA 2 , PLC, DAG, AEA, and PEA and symptom grading. PLA 2 (a), DAG 18:1 20:4 (b), DAG 18:0 20:4 (c), PLC (d), AEA (e), and PEA (f) were determined in six patients with symptom grading 0 , seven patients with grading 1 , five patients with grading 2 , and five patients with grading $3 .{ }^{*} p$ value $<0.05$ and ${ }^{* *} p$ value $<0.01 v s$. healthy controls. ${ }^{\S} p$ value $<0.01 v s$. patients with symptom grading 0 .

their concentrations are similar in indolent and advanced variants. Interestingly, DAG concentrations are positively correlated with those of their metabolite 2-AG, even though 2-AG concentrations are not altered. Other sources of DAGs and/or alternative biosynthetic precursors for 2-AG, rather than shortage of DAGL activity, might explain this finding. It is conceivable that the increased DAG concentrations in mastocytosis reflect altered PKC activation, essential for release of preformed mediators in MC granules [36], rather than the production of $2-\mathrm{AG}$, which by activating $\mathrm{CB}_{2}$ cannabinoid receptors would instead counteract this effect [40].
In addition to previously discovered molecules aimed at controlling cellular (MC) activation, $N$-acylethanolamines (for example, AEA and its congener PEA) are involved in endogenous, cannabinoid receptor-dependent and independent, protective mechanisms that are activated as a result of different types of tissue damage or stimulation of inflammatory responses and nociceptive fibers [70]. We mentioned above the large body of evidence indicating that PEA has anti-inflammatory actions and inhibits MC degranulation [40]. Thus, the increase of PEA plasma levels in mastocytosis could represent an attempt to control the activation of MCs. 


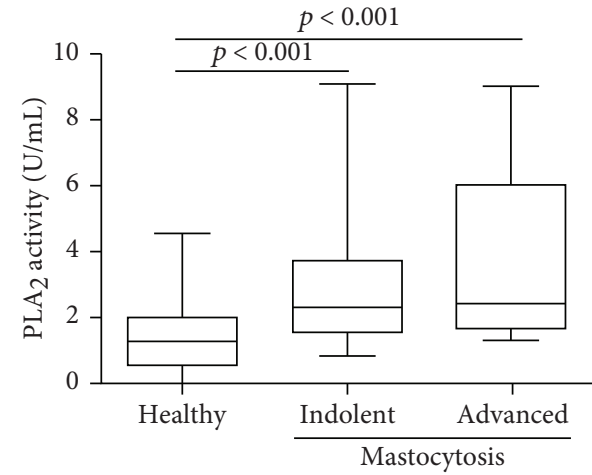

(a)

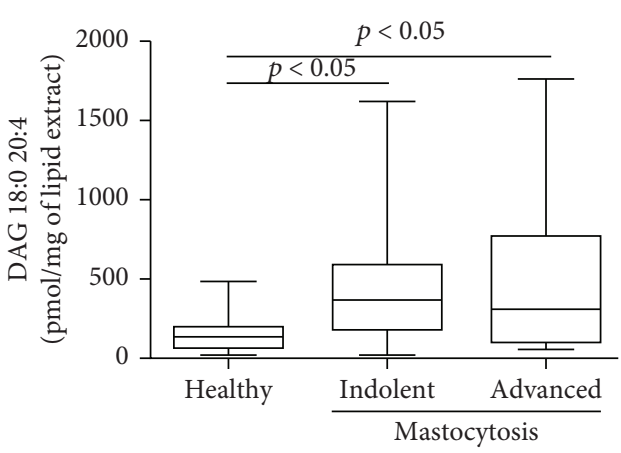

(c)

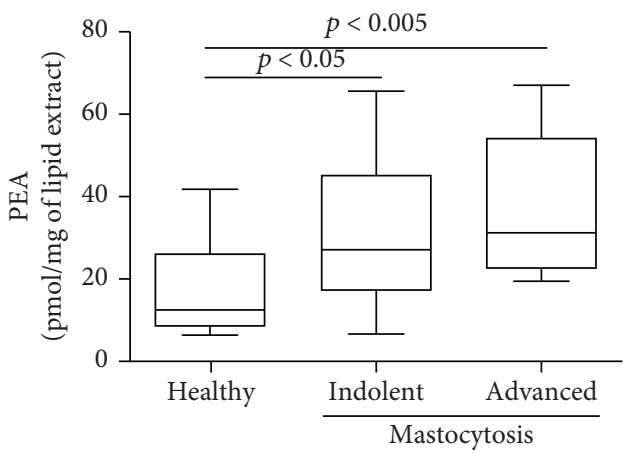

(e)

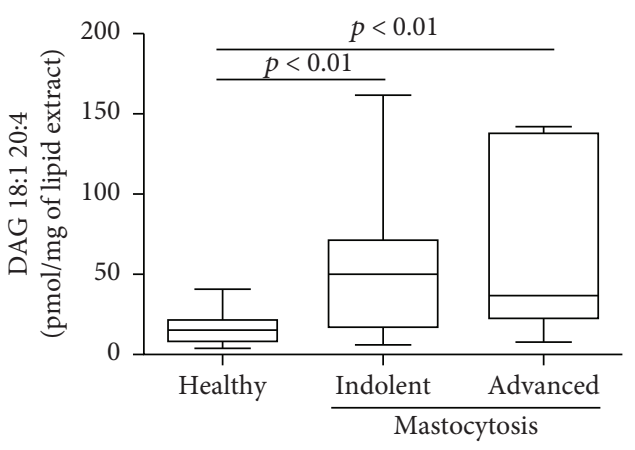

(b)

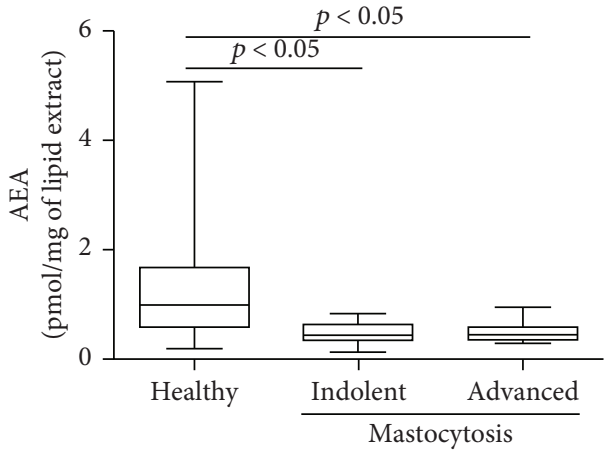

(d)

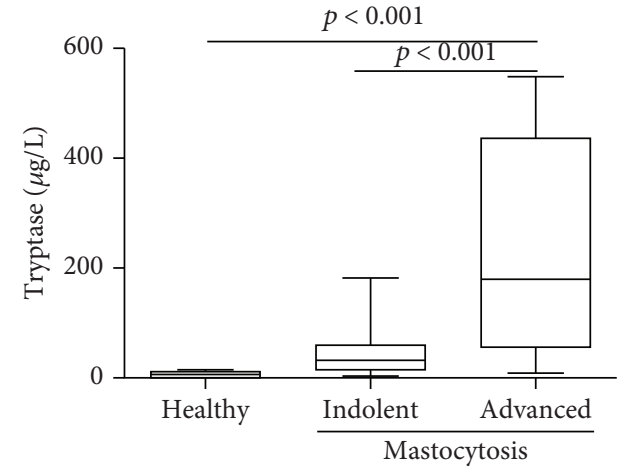

(f)

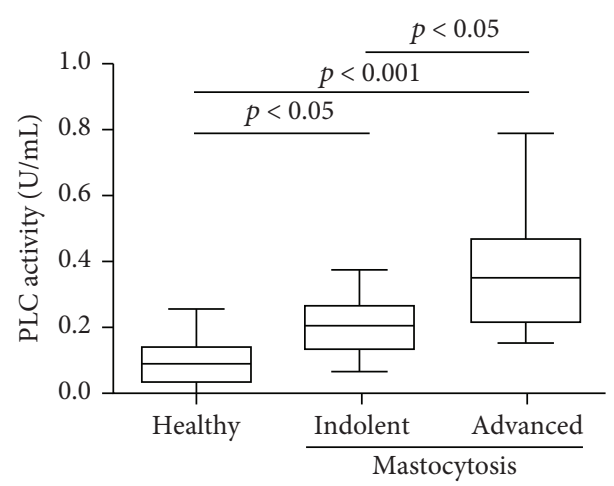

(g)

Figure 6: Relationships among PLA 2 , DAG, AEA, PEA, and PLC and mastocytosis clinical variants. PLA 2 (a), DAG 18:1 20:4 (b), DAG 18:0 20:4 (c), AEA (d), PEA (e), tryptase (f), and PLC (g) were determined in healthy controls and in 15 patients with indolent variants and 8 patients with advanced variants. 
By contrast, the decrease of AEA concentrations and its negative correlation with tryptase levels may contribute to the underlying inflammation associated with this disorder.

Human tryptase is considered highly specific of MCs, which may contain high amounts, up to $35 \mathrm{pg}$ per cell [71-73]. Although basophils may produce small quantities of tryptase, the vast majority of tryptase in the blood is derived by MCs [74, 75]. Detection of tryptase provides information about MC distribution, numbers, proliferation, and activation status [76] and is, therefore, a major marker of mast cell disorders, including mastocytosis $[44,56,77,78]$.

Unlike tryptase, PLs and the metabolites measured in this study are produced not only from MCs but also from other leukocytes such as neutrophils, eosinophils, and macrophages $[9,18,41,79-81]$. The biologic activity of PLs is not confined to MCs but includes other immune and nonimmune cells [41, 82-84]. Our data show that both $\mathrm{PLA}_{2}$ and PLC are increased in plasma of patients with mastocytosis and that there is a correlation between PLC activity and serum tryptase but not between $\mathrm{PLA}_{2}$ and tryptase. These results indicate that these enzymes are secreted by cells that are activated in mastocytosis, but they do not allow to discriminate whether they are released from MCs or by other cells that could be indirectly activated in these patients. On the other hand, the cellular sources of PLs, DAGs, and PEA in the plasma of patients with mastocytosis are unknown, and further studies are needed to understand the origin of these enzymes in these patients.

It has been shown that the KIT activation generates PLC signal, DAG formation, and PKC activation [85-87]. This study shows an increase of PLs in patients with more symptoms and with advanced form of mastocytosis. A question that remains to be answered is whether activating mutations of KIT lead to an abnormal PL activation that could contribute to the development of symptoms and to increase severity of mastocytosis. Future studies will compare the levels of PLs and their metabolites in patients with and without KIT mutation.

In conclusion, we demonstrate that plasma levels of PLs, DAGs, and some $\mathrm{N}$-acylethanolamines are altered in patients with mastocytosis and that PLC activity is further increased in patients with symptomatic and aggressive forms of disease. These results suggest a relevant but different and, in some cases, opposing role of these mediators in mastocytosis. Further studies are needed to evaluate the diagnostic and prognostic value of PLs, DAGs, and $N$-acylethanolamines in different forms of mastocytosis and to understand whether pharmacological blockade of these molecules (e.g., PKC) may improve the symptoms and severity of mastocytosis.
Abbreviations
AEA: Anandamide
AA: $\quad$ Arachidonic acid
ASM: $\quad$ Aggressive systemic mastocytosis
2-AG: 2-Arachidonoylglycerol
BMM: $\quad$ Bone marrow mastocytosis
CM: $\quad$ Cutaneous mastocytosis
DAGs: Diacylglycerols
DAGLs: DAG lipases

\begin{tabular}{|c|c|}
\hline Cs: & Endocannabinoids \\
\hline EIA: & Fluoroenzyme immune assay \\
\hline M: & Indolent systemic mastocytosis \\
\hline Cs: & Mast cells \\
\hline CM: & Maculopapular cutaneous mastocyt \\
\hline 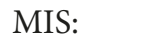 & Mastocytosis in the skin \\
\hline Ls: & Phospholipase enzymes \\
\hline EA: & Palmitoylethanolamide \\
\hline $\mathrm{GD}_{2}:$ & Prostaglandin $\mathrm{D}_{2}$ \\
\hline KC: & Protein kinase $\mathrm{C}$ \\
\hline EA: & Oleoylethanolamide \\
\hline $\mathrm{LA}_{2} \mathrm{~s}:$ & Secreted PLA 2 \\
\hline & Smouldering systemic mastocytosis \\
\hline & Systemic mastocytosis \\
\hline 1-AHD: & $\begin{array}{l}\text { Systemic mastocytosis associated with } \\
\text { ematologic disease }\end{array}$ \\
\hline & World Health Organization. \\
\hline
\end{tabular}

\section{Data Availability}

All data are fully available without restriction. All relevant data are within the paper and its supporting information files.

\section{Conflicts of Interest}

The authors declare that they have no conflicts of interest.

\section{Authors' Contributions}

The authors who conducted experiments are Loffredo S., Ferrara A. L., Galdiero M. R., and Piscitelli F. Those who worked on clinical enrollment are Petraroli A., Triggiani M., Parente R., Marone G., and Varricchi G. And those who performed data analysis are Loffredo S., Ferrara A. L., Di Marzo V., Parente R., Marone G., and Piscitelli F. All authors participated in research design and wrote or contributed to the writing of the manuscript.

\section{Acknowledgments}

The authors thank scientists from CISI Laboratory not listed as authors for invaluable collaborations and administrative staff (Dr. Roberto Bifulco and Dr. Anna Ferraro), without whom we could not function as an integrated team. This work was supported in part by grants from the Regione Campania CISI-Lab Project, CRèME Project, and TIMING Project.

\section{Supplementary Materials}

Supplementary Table 1: the variants of systemic mastocytosis (SM). Supplementary Figure 1: the correlation between DAG 18:1 20:4 and DAG 18:0 20:4 in plasma of patients with mastocytosis. Supplementary Figure 2: the correlation between PLC and DAGs in plasma of patients with mastocytosis. Supplementary Figure 3: the relationship between AEA, PEA, and OEA concentrations and gender of patients with mastocytosis and healthy controls. (Supplementary Materials) 


\section{References}

[1] P. Valent, C. Akin, L. Escribano et al., "Standards and standardization in mastocytosis: consensus statements on diagnostics, treatment recommendations and response criteria," European Journal of Clinical Investigation, vol. 37, no. 6, pp. 435-453, 2007.

[2] D. D. Metcalfe and Y. A. Mekori, "Pathogenesis and pathology of mastocytosis," Annual Review of Pathology, vol. 12, no. 1, pp. 487-514, 2017.

[3] P. Valent, C. Akin, K. Hartmann et al., "Advances in the classification and treatment of mastocytosis: current status and outlook toward the future," Cancer Research, vol. 77, no. 6, pp. 1261-1270, 2017.

[4] P. Valent, C. Akin, and D. D. Metcalfe, "Mastocytosis: 2016 updated WHO classification and novel emerging treatment concepts," Blood, vol. 129, no. 11, pp. 1420-1427, 2017.

[5] C. Akin, "Mast cell activation syndromes," The Journal of Allergy and Clinical Immunology, vol. 140, no. 2, pp. 349355, 2017.

[6] A. Schuch and K. Brockow, "Mastocytosis and anaphylaxis," Immunology and Allergy Clinics of North America, vol. 37, no. 1, pp. 153-164, 2017.

[7] D. D. Metcalfe, "Mast cells and mastocytosis," Blood, vol. 112, no. 4, pp. 946-956, 2008.

[8] T. C. Moon, A. D. Befus, and M. Kulka, "Mast cell mediators: their differential release and the secretory pathways involved," Frontiers in Immunology, vol. 5, 2014.

[9] M. Murakami and Y. Taketomi, "Secreted phospholipase A2 and mast cells," Allergology International, vol. 64, no. 1, pp. 4-10, 2015.

[10] M. Zhu, J. Zou, T. Li et al., "Differential Roles of Phospholipase D Proteins in FceRI-Mediated Signaling and Mast Cell Function," Journal of Immunology, vol. 195, no. 9, pp. 44924502, 2015.

[11] L. Ramrakhiani and S. Chand, "Recent progress on phospholipases: different sources, assay methods, industrial potential and pathogenicity," Applied Biochemistry and Biotechnology, vol. 164, no. 7, pp. 991-1022, 2011.

[12] M. Murakami, Y. Taketomi, Y. Miki, H. Sato, T. Hirabayashi, and K. Yamamoto, "Recent progress in phospholipase A2 research: From cells to animals to humans," Progress in Lipid Research, vol. 50, no. 2, pp. 152-192, 2011.

[13] A. B. Fisher and M. Jain, Phospholipases: Degradation of Phospholipids in Membranes and Emulsions, eLS, 2009.

[14] T. O. Eichmann and A. Lass, "DAG tales: the multiple faces of diacylglycerol-stereochemistry, metabolism, and signaling," Cellular and Molecular Life Sciences, vol. 72, no. 20, pp. 3931-3952, 2015.

[15] J. A. Boyce, "Mast cells and eicosanoid mediators: a system of reciprocal paracrine and autocrine regulation," Immunological Reviews, vol. 217, no. 1, pp. 168-185, 2007.

[16] L. Aloe, A. Leon, and R. Levi-Montalcini, "A proposed autacoid mechanism controlling mastocyte behaviour," Agents and Actions, vol. 39, no. S1, pp. C145-C147, 1993.

[17] S. P. Chock, E. A. Schmauder-Chock, E. Cordella-Miele, L. Miele, and A. B. Mukherjee, "The localization of phospholipase A2 in the secretory granule," The Biochemical Journal, vol. 300, no. 3, pp. 619-622, 1994, Pt 3.

[18] M. Triggiani, G. Giannattasio, C. Calabrese et al., "Lung mast cells are a source of secreted phospholipases A2," Journal of
Allergy and Clinical Immunology, vol. 124, no. 3, pp. 558565.e3, 2009.

[19] F. Granata, V. Nardicchi, S. Loffredo et al., "Secreted phospholipases $\mathrm{A}(2)$ : a proinflammatory connection between macrophages and mast cells in the human lung," Immunobiology, vol. 214, no. 9-10, pp. 811-821, 2009.

[20] T. S. Hallstrand, Y. Lai, Z. Ni et al., "Relationship between levels of secreted phospholipase A2 groups IIA and X in the airways and asthma severity," Clinical and Experimental Allergy, vol. 41, no. 6, pp. 801-810, 2011.

[21] F. Granata, R. I. Staiano, S. Loffredo et al., "The role of mast cell-derived secreted phospholipases A2 in respiratory allergy," Biochimie, vol. 92, no. 6, pp. 588-593, 2010.

[22] E. A. Dennis, J. Cao, Y. H. Hsu, V. Magrioti, and G. Kokotos, "Phospholipase A2 enzymes: physical structure, biological function, disease implication, chemical inhibition, and therapeutic intervention," Chemical Reviews, vol. 111, no. 10, pp. 6130-6185, 2011.

[23] M. Menschikowski, A. Hagelgans, U. Schuler, S. Froeschke, A. Rosner, and G. Siegert, "Plasma levels of phospholipase A2-IIA in patients with different types of malignancies: prognosis and association with inflammatory and coagulation biomarkers," Pathology Oncology Research, vol. 19, no. 4, pp. 839-846, 2013.

[24] M. Murakami, K. Yamamoto, Y. Miki, R. Murase, H. Sato, and Y. Taketomi, "The roles of the secreted phospholipase A2 gene family in immunology," Advances in Immunology, vol. 132, pp. 91-134, 2016.

[25] V. Brglez, G. Lambeau, and T. Petan, "Secreted phospholipases A2 in cancer: diverse mechanisms of action," Biochimie, vol. 107, Part A, pp. 114-123, 2014.

[26] D. Bernard and D. Vindrieux, "PLA2R1: expression and function in cancer," Biochimica et Biophysica Acta, vol. 1846, no. 1, pp. 40-44, 2014.

[27] E. Boilard, S. G. Bourgoin, C. Bernatchez, P. E. Poubelle, and M. E. Surette, "Interaction of low molecular weight group IIA phospholipase A2 with apoptotic human T cells: role of heparan sulfate proteoglycans," The FASEB Journal, vol. 17, no. 9, pp. 1068-1080, 2003.

[28] M. Fujita, K. Zhu, C. K. Fujita et al., "Proinflammatory Secreted Phospholipase A2 Type IIA (sPLA-IIA) Induces Integrin Activation through Direct Binding to a Newly Identified Binding Site (Site 2) in Integrins $\alpha \mathrm{v} \beta 3, \alpha 4 \beta 1$, and $\alpha 5 \beta 1$," Journal of Biological Chemistry, vol. 290, no. 1, pp. 259-271, 2015.

[29] G. Lambeau and M. H. Gelb, "Biochemistry and physiology of mammalian secreted phospholipases A2," Annual Review of Biochemistry, vol. 77, no. 1, pp. 495-520, 2008.

[30] M. Murakami, N. Hara, I. Kudo, and K. Inoue, "Triggering of degranulation in mast cells by exogenous type II phospholipase A2," The Journal of Immunology, vol. 151, no. 10, pp. 5675-5684, 1993.

[31] J. D. Morrow, C. Guzzo, G. Lazarus, J. A. Oates, and L. Jackson Roberts II, "Improved diagnosis of mastocytosis by measurement of the major urinary metabolite of prostaglandin D2," Journal of Investigative Dermatology, vol. 104, no. 6, pp. 937940, 1995.

[32] R. J. T. OUWENDIJK, F. J. ZIJLSTRA, J. H. P. WILSON, I. L. BONTA, J. E. VINCENT, and E. STOLZ, "Raised plasma levels of thromboxane B2in systemic mastocytosis," European Journal of Clinical Investigation, vol. 13, no. 3, pp. 227-229, 1983. 
[33] J. D. Morrow, J. A. Oates, L. Jackson Roberts II et al., "Increased Formation of ThromboxaneIn Vivo in Humans with Mastocytosis," The Journal of Investigative Dermatology, vol. 113, no. 1, pp. 93-97, 1999.

[34] C. Akin and D. D. Metcalfe, "Surrogate markers of disease in mastocytosis," International Archives of Allergy and Immunology, vol. 127, no. 2, pp. 133-136, 2002.

[35] W. Xiao, J.-i. Kashiwakura, H. Hong et al., "Phospholipase C- $\beta 3$ Regulates FceRI-Mediated Mast Cell Activation by Recruiting the Protein Phosphatase SHP-1," Immunity, vol. 34, no. 6, pp. 893-904, 2011.

[36] Z. Peng and M. A. Beaven, "An essential role for phospholipase $\mathrm{D}$ in the activation of protein kinase $\mathrm{C}$ and degranulation in mast cells," Journal of Immunology, vol. 174, no. 9, pp. 5201-5208, 2005.

[37] A. Chahdi, W. S. Choi, Y. M. Kim, P. F. Fraundorfer, and M. A. Beaven, "Serine/threonine protein kinases synergistically regulate phospholipase D1 and 2 and secretion in RBL-2H3 mast cells," Molecular Immunology, vol. 38, no. 16-18, pp. 1269-1276, 2002.

[38] P. Lin, W. J. Fung, and A. M. Gilfillan, "Phosphatidylcholinespecific phospholipase D-derived 1,2-diacylglycerol does not initiate protein kinase $\mathrm{C}$ activation in the RBL $2 \mathrm{H} 3$ mast-cell line," The Biochemical Journal, vol. 287, no. 1, pp. 325-331, 1992, Pt 1.

[39] D. A. Kennerly, "Phosphatidylcholine is a quantitatively more important source of increased 1,2-diacylglycerol than is phosphatidylinositol in mast cells," The Journal of Immunology, vol. 144, no. 10, pp. 3912-3919, 1990.

[40] M. Reisenberg, P. K. Singh, G. Williams, and P. Doherty, “The diacylglycerol lipases: structure, regulation and roles in and beyond endocannabinoid signalling," Philosophical Transactions of the Royal Society of London. Series B, Biological Sciences, vol. 367, no. 1607, pp. 3264-3275, 2012.

[41] R. I. Staiano, S. Loffredo, F. Borriello et al., "Human lungresident macrophages express $\mathrm{CB} 1$ and $\mathrm{CB} 2$ receptors whose activation inhibits the release of angiogenic and lymphangiogenic factors," Journal of Leukocyte Biology, vol. 99, no. 4, pp. 531-540, 2016.

[42] A. Luchicchi and M. Pistis, "Anandamide and 2-arachidonoylglycerol: pharmacological properties, functional features, and emerging specificities of the two major endocannabinoids," Molecular Neurobiology, vol. 46, no. 2, pp. 374-392, 2012.

[43] L. Facci, R. Dal Toso, S. Romanello, A. Buriani, S. D. Skaper, and A. Leon, "Mast cells express a peripheral cannabinoid receptor with differential sensitivity to anandamide and palmitoylethanolamide," Proceedings of the National Academy of Sciences of the United States of America, vol. 92, no. 8, pp. 3376-3380, 1995.

[44] W. R. Sperr, J. H. Jordan, M. Fiegl et al., "Serum tryptase levels in patients with mastocytosis: correlation with mast cell burden and implication for defining the category of disease," International Archives of Allergy and Immunology, vol. 128, no. 2, pp. 136-141, 2002.

[45] S. D. Skaper, L. Facci, and P. Giusti, "Glia and mast cells as targets for palmitoylethanolamide, an anti-inflammatory and neuroprotective lipid mediator," Molecular Neurobiology, vol. 48, no. 2, pp. 340-352, 2013.

[46] D. De Filippis, A. D’Amico, M. P. Cinelli, G. Esposito, V. Di Marzo, and T. Iuvone, "Adelmidrol, a palmitoylethanolamide analogue, reduces chronic inflammation in a carrageenin- granuloma model in rats," Journal of Cellular and Molecular Medicine, vol. 13, no. 6, pp. 1086-1095, 2009.

[47] F. Roviezzo, A. Rossi, E. Caiazzo et al., "Palmitoylethanolamide supplementation during sensitization prevents airway allergic symptoms in the mouse," Frontiers in Pharmacology, vol. 8, p. 857, 2017.

[48] S. Cerrato, P. Brazis, M. F. della Valle, A. Miolo, and A. Puigdemont, "Effects of palmitoylethanolamide on immunologically induced histamine, PGD2 and TNF $\alpha$ release from canine skin mast cells," Veterinary Immunology and Immunopathology, vol. 133, no. 1, pp. 9-15, 2010.

[49] A. H. Y. Lau and S. S. M. Chow, "Effects of cannabinoid receptor agonists on immunologically induced histamine release from rat peritoneal mast cells," European Journal of Pharmacology, vol. 464, no. 2-3, pp. 229-235, 2003.

[50] G. A. Cabral, G. A. Ferreira, and M. J. Jamerson, "Endocannabinoids and the immune system in health and disease," Handbook of Experimental Pharmacology, vol. 231, pp. 185-211, 2015.

[51] S. L. Cruz, E. Sanchez-Miranda, J. I. Castillo-Arellano, R. D. Cervantes-Villagrana, A. Ibarra-Sanchez, and C. GonzalezEspinosa, "Anandamide inhibits FceRI-dependent degranulation and cytokine synthesis in mast cells through $\mathrm{CB}_{2}$ and GPR55 receptor activation. Possible involvement of $\mathrm{CB}_{2}$ GPR55 heteromers," International Immunopharmacology, vol. 64, pp. 298-307, 2018.

[52] A. Pardanani, "Systemic mastocytosis in adults: 2017 update on diagnosis, risk stratification and management," American Journal of Hematology, vol. 91, no. 11, pp. 11461159, 2016.

[53] M. Arock, K. Sotlar, C. Akin et al., "KIT mutation analysis in mast cell neoplasms: recommendations of the European Competence Network on Mastocytosis," Leukemia, vol. 29, no. 6, pp. 1223-1232, 2015.

[54] I. Matias, G. Carta, E. Murru, S. Petrosino, S. Banni, and V. Di Marzo, "Effect of polyunsaturated fatty acids on endocannabinoid and $\mathrm{N}$-acyl-ethanolamine levels in mouse adipocytes," Biochimica et Biophysica Acta, vol. 1781, no. 1-2, pp. 52-60, 2008.

[55] F. Piscitelli, G. Carta, T. Bisogno et al., "Effect of dietary krill oil supplementation on the endocannabinoidome of metabolically relevant tissues from high-fat-fed mice," Nutrition \& Metabolism (London), vol. 8, no. 1, p. 51, 2011.

[56] K. H. Lim, A. Tefferi, T. L. Lasho et al., "Systemic mastocytosis in 342 consecutive adults: survival studies and prognostic factors," Blood, vol. 113, no. 23, pp. 5727-5736, 2009.

[57] J. H. Butterfield, "Survey of aspirin administration in systemic mastocytosis," Prostaglandins \& Other Lipid Mediators, vol. 88, no. 3-4, pp. 122-124, 2009.

[58] A. Pardanani, "How I treat patients with indolent and smoldering mastocytosis (rare conditions but difficult to manage)," Blood, vol. 121, no. 16, pp. 3085-3094, 2013.

[59] E. Kikawada, J. V. Bonventre, and J. P. Arm, “Group V secretory PLA2 regulates TLR2-dependent eicosanoid generation in mouse mast cells through amplification of ERK and cPLA2alpha activation," Blood, vol. 110, no. 2, pp. 561-567, 2007.

[60] M. Murakami, I. Kudo, and K. Inoue, "Eicosanoid generation from antigen-primed mast cells by extracellular mammalian 14-kDa group II phospholipase A2," FEBS Letters, vol. 294, no. 3, pp. 247-251, 1991. 
[61] H. Sato, Y. Taketomi, Y. Isogai et al., "Group III secreted phospholipase A2 transgenic mice spontaneously develop inflammation," The Biochemical Journal, vol. 421, no. 1, pp. 17-27, 2009.

[62] Y. Taketomi, N. Ueno, T. Kojima et al., "Mast cell maturation is driven via a group III phospholipase A2-prostaglandin D2DP1 receptor paracrine axis," Nature Immunology, vol. 14, no. 6, pp. 554-563, 2013.

[63] J. O. Gronroos, J. H. Salonen, M. Viander, T. J. Nevalainen, and V. J. O. Laine, "Roles of group IIA phospholipase A2 and complement in killing of bacteria by acute phase serum," Scandinavian Journal of Immunology, vol. 62, no. 4, pp. 413419, 2005.

[64] E. Kupert, M. Anderson, Y. Liu et al., "Plasma secretory phospholipase A2-IIa as a potential biomarker for lung cancer in patients with solitary pulmonary nodules," BMC Cancer, vol. 11 , no. $1,2011$.

[65] Z. Mallat, G. Lambeau, and A. Tedgui, "LipoproteinAssociated and Secreted Phospholipases $\mathrm{A}_{2}$ in Cardiovascular Disease," Circulation, vol. 122, no. 21, pp. 2183-2200, 2010.

[66] T. J. Nevalainen, L. I. Eerola, E. Rintala, V. J. O. Laine, G. Lambeau, and M. H. Gelb, "Time-resolved fluoroimmunoassays of the complete set of secreted phospholipases A2 in human serum," Biochimica et Biophysica Acta, vol. 1733, no. 2-3, pp. 210-223, 2005.

[67] S. Loffredo, A. L. Ferrara, M. Bova et al., "Secreted phospholipases A2 in hereditary angioedema with C1-inhibitor deficiency," Frontiers in Immunology, vol. 9, p. 1721, 2018.

[68] A. Matito, J. M. Morgado, I. Álvarez-Twose et al., "Serum tryptase monitoring in indolent systemic mastocytosis: association with disease features and patient outcome," PLoS One, vol. 8, no. 10, article e76116, 2013.

[69] J. Hallgren and G. Pejler, "Biology of mast cell tryptase. An inflammatory mediator," The FEBS Journal, vol. 273, no. 9, pp. 1871-1895, 2006.

[70] P. Pacher, S. Batkai, and G. Kunos, "The endocannabinoid system as an emerging target of pharmacotherapy," Pharmacological Reviews, vol. 58, no. 3, pp. 389-462, 2006.

[71] L. SCHWARTZ, "Tryptase, a mediator of human mast cells," The Journal of Allergy and Clinical Immunology, vol. 86, no. 4, pp. 594-598, 1990, Pt 2.

[72] J. Vitte, "Human mast cell tryptase in biology and medicine," Molecular Immunology, vol. 63, no. 1, pp. 18-24, 2015.

[73] H. P. McNeil, R. Adachi, and R. L. Stevens, "Mast Cellrestricted Tryptases: Structure and Function in Inflammation and Pathogen Defense," Journal of Biological Chemistry, vol. 282, no. 29, pp. 20785-20789, 2007.

[74] M. C. Castells, A. M. Irani, and L. B. Schwartz, "Evaluation of human peripheral blood leukocytes for mast cell tryptase," The Journal of Immunology, vol. 138, no. 7, pp. 2184-2189, 1987.

[75] S. Jogie-Brahim, H. K. Min, Y. Fukuoka, H. Z. Xia, and L. B. Schwartz, "Expression of alpha-tryptase and beta-tryptase by human basophils," The Journal of Allergy and Clinical Immunology, vol. 113, no. 6, pp. 1086-1092, 2004.

[76] P. Valent, "Mast cell activation syndromes: definition and classification," Allergy, vol. 68, no. 4, pp. 417-424, 2013.

[77] L. B. Schwartz, "Diagnostic value of tryptase in anaphylaxis and mastocytosis," Immunology and Allergy Clinics of North America, vol. 26, no. 3, pp. 451-463, 2006.

[78] P. Valent, H. P. Horny, M. Triggiani, and M. Arock, "Clinical and laboratory parameters of mast cell activation as basis for the formulation of diagnostic criteria," International Archives of Allergy and Immunology, vol. 156, no. 2, pp. 119-127, 2011.

[79] N. Degousee, F. Ghomashchi, E. Stefanski et al., "Groups IV, $\mathrm{V}$, and $\mathrm{X}$ phospholipases A2s in human neutrophils: role in eicosanoid production and gram-negative bacterial phospholipid hydrolysis," The Journal of Biological Chemistry, vol. 277, no. 7, pp. 5061-5073, 2002.

[80] T. Kawakami and W. Xiao, "Phospholipase C- $\beta$ in immune cells," Advances in Biological Regulation, vol. 53, no. 3, pp. 249-257, 2013.

[81] T. S. Hallstrand, Y. Lai, K. A. Hooper et al., "Endogenous secreted phospholipase A2 group X regulates cysteinyl leukotrienes synthesis by human eosinophils," The Journal of Allergy and Clinical Immunology, vol. 137, no. 1, pp. 268-277.e8, 2016.

[82] F. Granata, A. Frattini, S. Loffredo et al., "Production of vascular endothelial growth factors from human lung macrophages induced by group IIA and group X secreted phospholipases A2," Journal of Immunology, vol. 184, no. 9, pp. 52325241, 2010.

[83] M. Triggiani, F. Granata, A. Frattini, and G. Marone, "Activation of human inflammatory cells by secreted phospholipases A2," Biochimica et Biophysica Acta, vol. 1761, no. 11, pp. 1289-1300, 2006.

[84] F. Chouinard, J. S. Lefebvre, P. Navarro et al., "The endocannabinoid 2-arachidonoyl-glycerol activates human neutrophils: critical role of Its hydrolysis and de novo leukotriene B4 biosynthesis," Journal of Immunology, vol. 186, no. 5, pp. 3188-3196, 2011.

[85] J. Liang, Y. L. Wu, B. J. Chen, W. Zhang, Y. Tanaka, and H. Sugiyama, "The C-kit receptor-mediated signal transduction and tumor-related diseases," International Journal of Biological Sciences, vol. 9, no. 5, pp. 435-443, 2013.

[86] K. Vosseller, G. Stella, N. S. Yee, and P. Besmer, "c-kit receptor signaling through its phosphatidylinositide-3'-kinase-binding site and protein kinase C: role in mast cell enhancement of degranulation, adhesion, and membrane ruffling," Molecular Biology of the Cell, vol. 8, no. 5, pp. 909-922, 1997.

[87] O. Kozawa, P. Blume-Jensen, C. H. Heldin, and L. Ronnstrand, "Involvement of phosphatidylinositol 3'-kinase in stem-cellfactor-induced phospholipase D activation and arachidonic acid release," European Journal of Biochemistry, vol. 248, no. 1, pp. 149-155, 1997. 


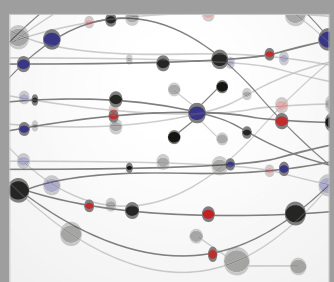

The Scientific World Journal
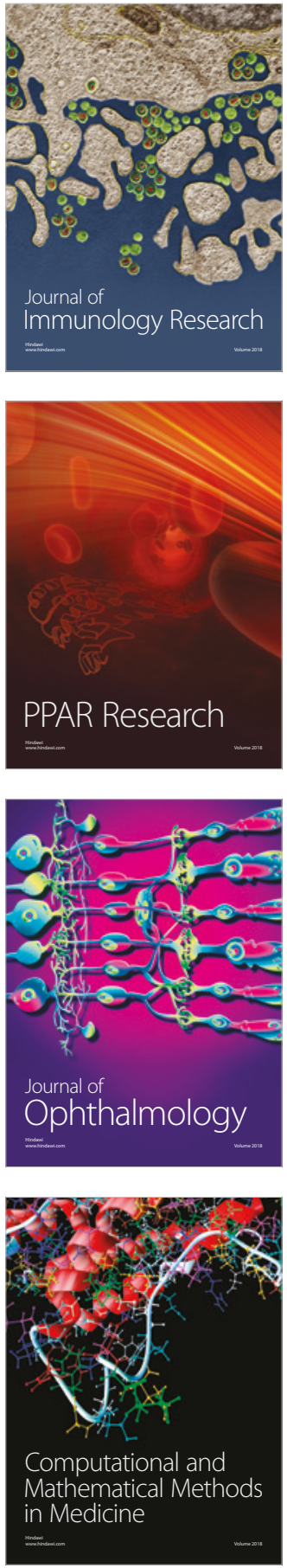

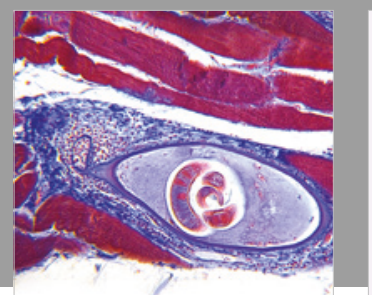

Gastroenterology Research and Practice

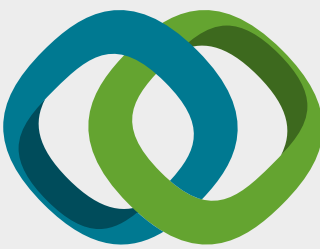

\section{Hindawi}

Submit your manuscripts at

www.hindawi.com
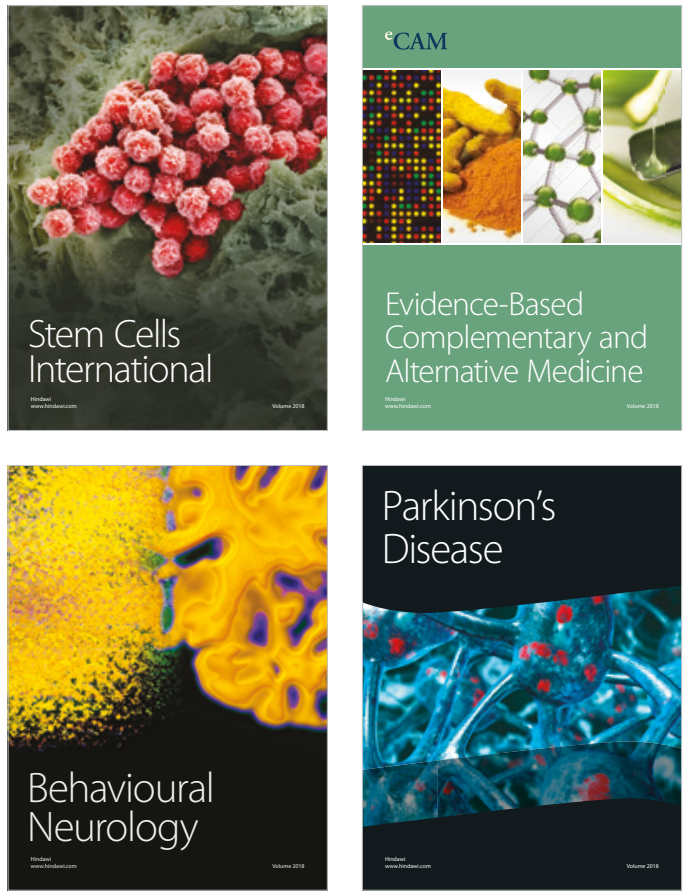

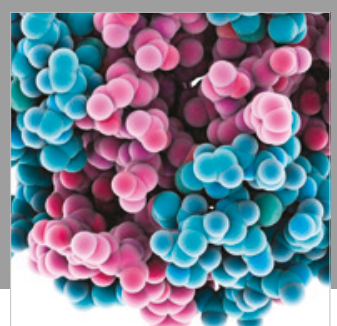

ournal of

Diabetes Research

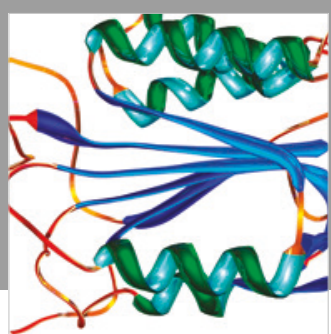

Disease Markers
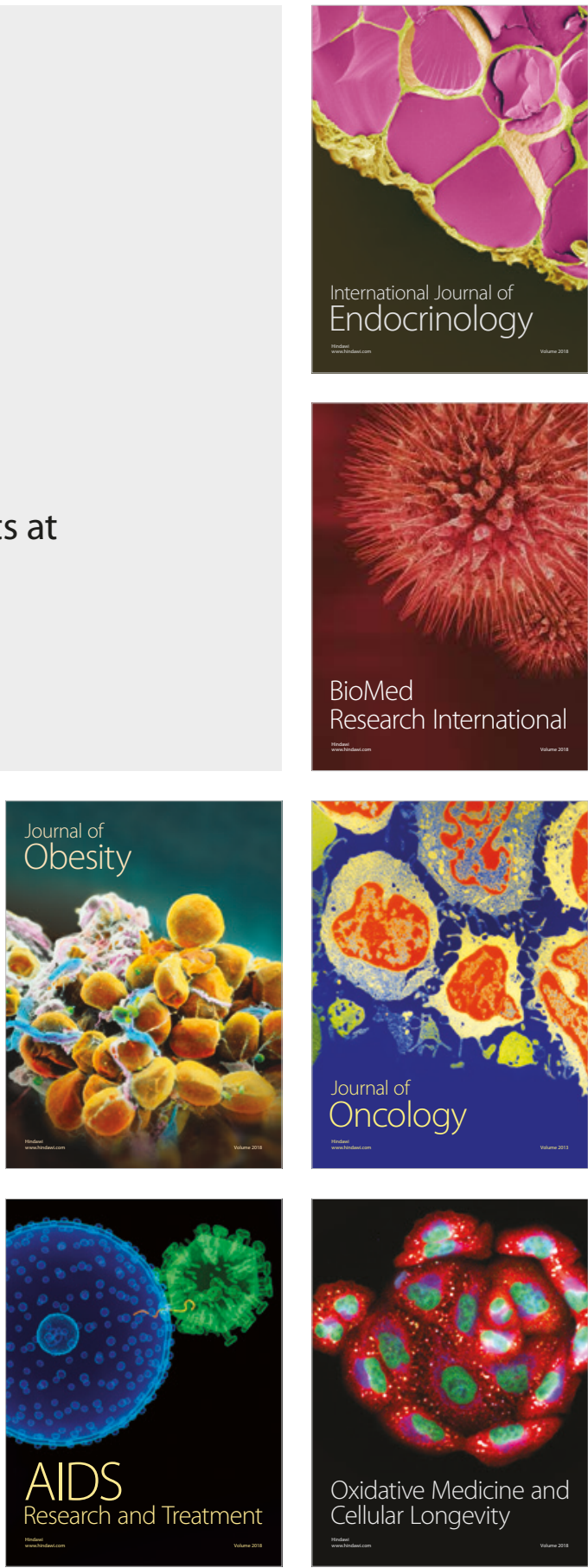